Bull. Fac. Agric., Cairo Univ., 69:277-290(2018).

\title{
POWER STRUCTURE OF RURAL FAMILY IN THE NEW VALLEY GOVERNORATE FROM GENDER PERSPECTIVE
}

(Received: 19.11.2018)

\author{
By \\ Hend M. Diab \\ Department of Rural Sociology and Agricultural Extension, Faculty of Agriculture, \\ Ain Shams University, Egypt.
}

\begin{abstract}
The present research aimed to identify the structure of power within the rural family from gender perspective by: 1) Identifying the extent of gender participation in making some family decisions, 2) Identifing the gender-specific differences in gender participation in decision-making within the family, 3) Drawing decision-making / authority according to gender in the family, 4) Identifing the factors of forming power within the family from a gender perspective, and 5) Identification of specific differences in the factors of power formation within the rural family. In order to achieve the study's objectives, the New Valley Governorate was selected as a geographical framework for conducting the empirical study. The data were collected through a survey questionnaire form from 100 households for the husbands and their wives through personal interviews in El-Khartoum village of El-Kharga district during the period from February to March 2018. The results showed a similarity between men and women in the highest frequent decisions in rural family. For men it was the purchase or sale of the agricultural machinery $(89.5 \%, 71.5 \%)$, the house $(85 \%, 69 \%)$, agricultural lands $(80.5 \%, 78 \%)>$ while for women, it was the type of food required for family members $(86.5 \%, 78.5 \%)$, purchase and type of cloths for family members $(82 \%, 71 \%)$, purchase or sale of domestic birds $(71 \%, 60 \%)$, respectively. In terms of the opinion of both men and women in the participation of male and female children in the family's decisions, the results indicated that men indicated that the participation of male children in decisions to buy or sell agricultural machinery at a rate of $38 \%$, and for female children the decision to buy, and determine the type of clothes for family members was $34 \%$. While, for the women point of view, the participation on type of food required for family members $(29.5 \%, 27.5 \%)$, the decision to purchase and the type of clothing for family members (28\% and $26.5 \%)$ for male and female children, respectively. Despite this similarity, the study showed significant differences between the views of both men and women regarding gender participation in decision-making within the family. Regarding factors of forming power within the family, the results revealed that socialization ranked first among the factors of forming power $(90 \%, 85.8 \%)$ followed by customs and traditions (87.4\% and $85.4 \%$ ), while the gender placed ranked third (83.40 And 82.2\%), from the perspective of male and female respondents, respectively. This is in line with the finding of non-significant differences between the opinions of men and women regarding power-forming factors within the rural family in the study area.
\end{abstract}

Keywords: Rural family, Power, Family decisions, Social system, Gender, New Valley

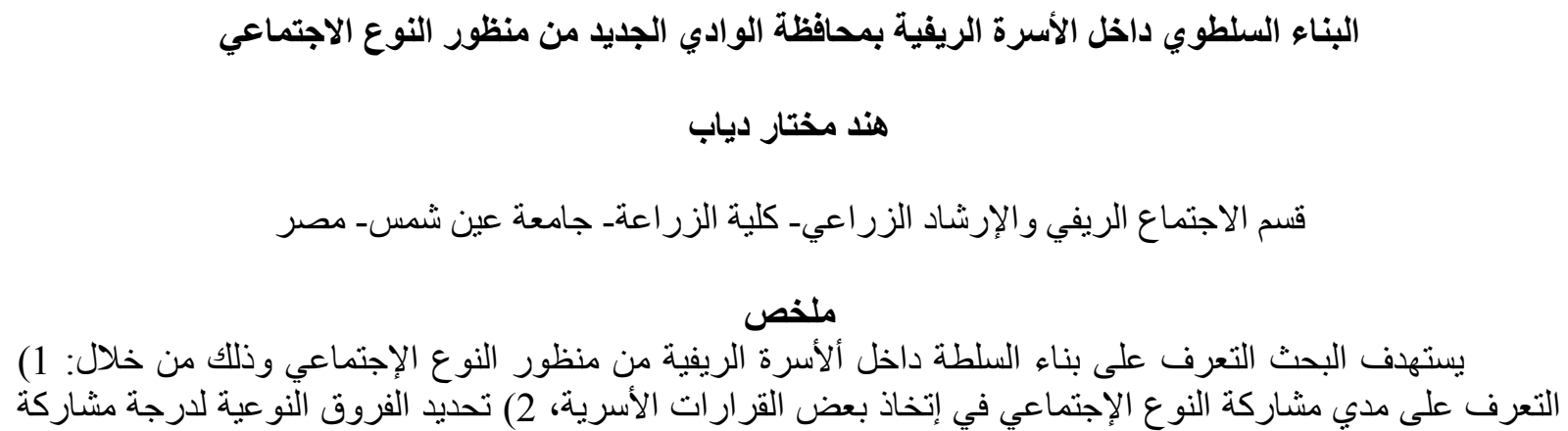




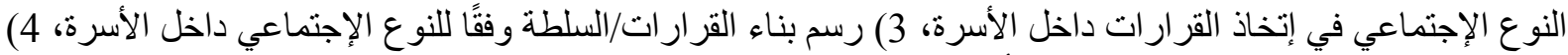

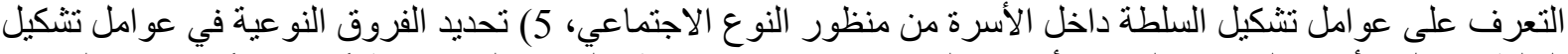

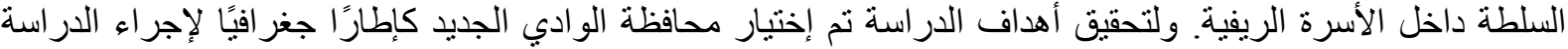

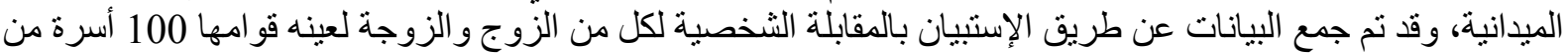

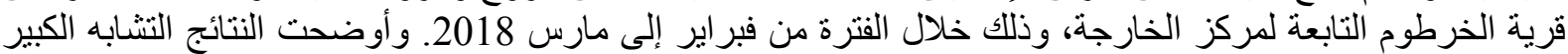

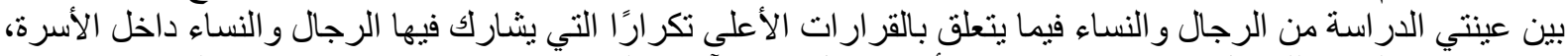

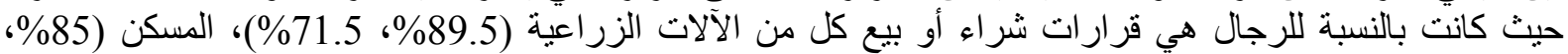

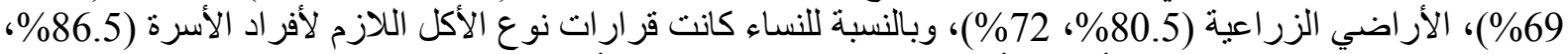

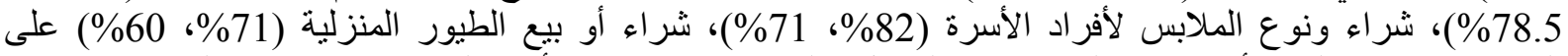

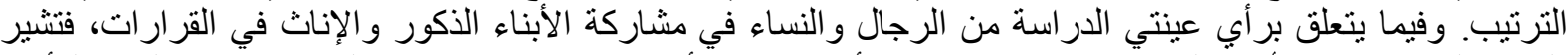

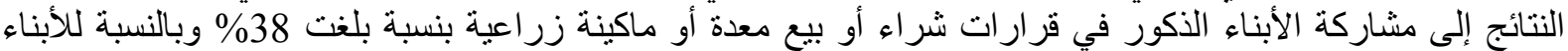

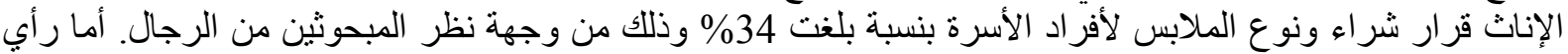

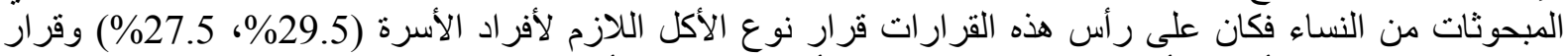

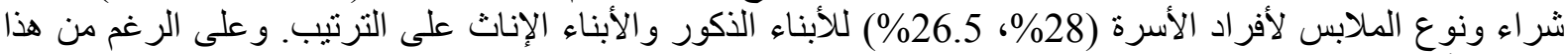

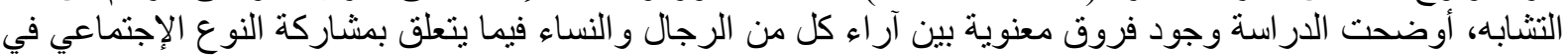

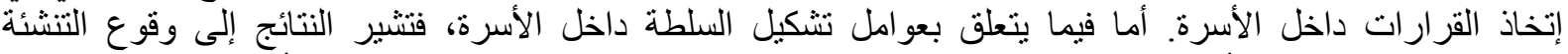

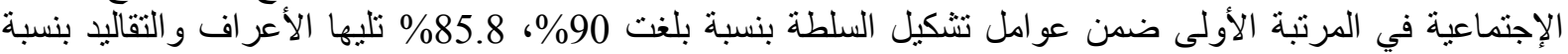

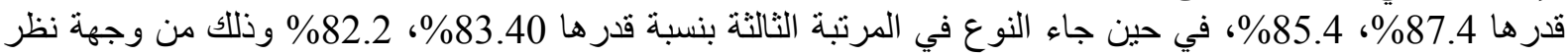

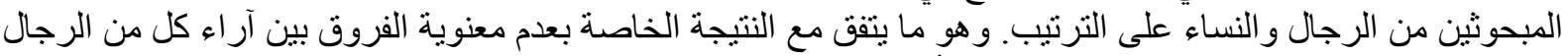
و السيدات المتعلقة بعو امل تشكيل السلطة داخل النس الأسرة.

اختلاف مستوياتها البسيطة منها والمعقدة تسير وفق فئق

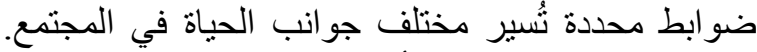
ولعل هذا ما يفسر تعدد أنواع السلطة إلى سلطة دئة دينية

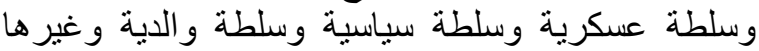

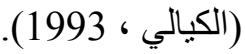

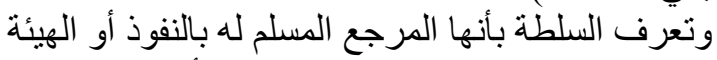

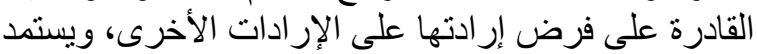

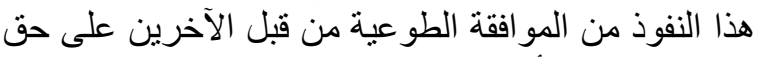

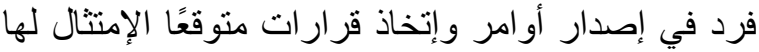

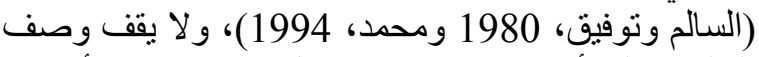

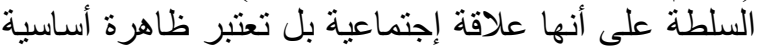

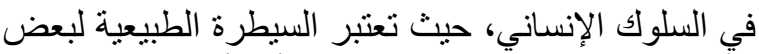

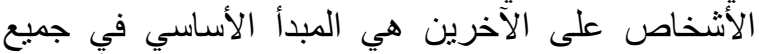

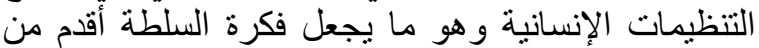

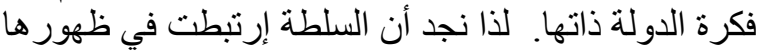

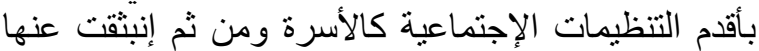

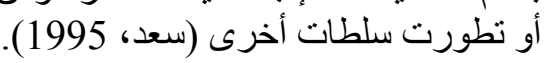

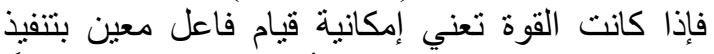

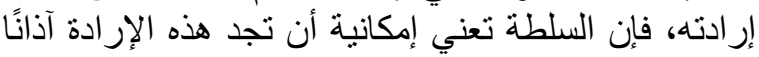

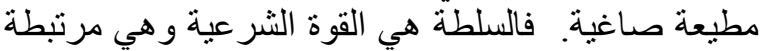

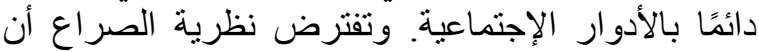

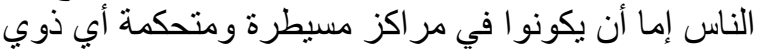

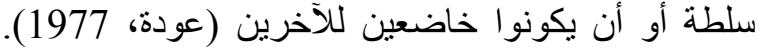
وتعرف السلطة داخل الأسرة بأنها القدرة الكامنة لأحد

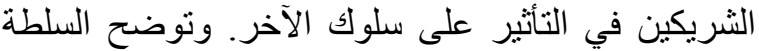
القدرة على إتخاذ القرار ات المؤثرة في حياة العائلة (ز ايد،

. 2008

وتثبير العديد من الثواهد إلى تمتع الأب بسلطة واسعة التبات النطاق على جميع أفراد الأسرة في العديد من المجتمعات

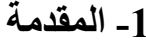

يعتبر النظام الأسري في نظر كثثر من الباحثين من أهم الأم

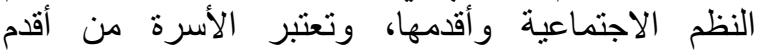

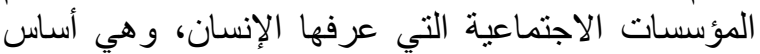

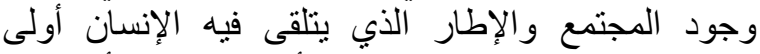

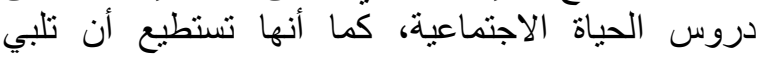

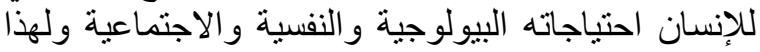

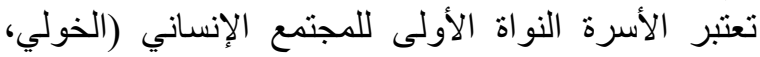
. (191 191

و الأسرة موجودة في كل المجتمعات الإنسانية عبر المبر

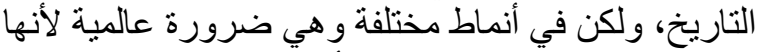
تقوم بإنجاز عدد من الوظائف الأساسية للمحافظة على على بقاء

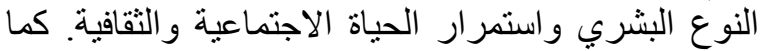

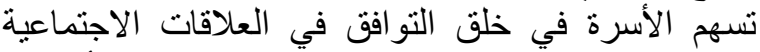
داخل المجتمع. وهي التي تعمل على توسيع وتيع مدارك أفر ادها

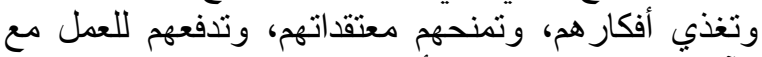
الآخرين وغيرها من الأعمال والواجيات واتيات التي تمارسها

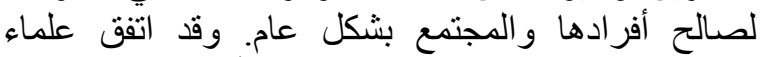

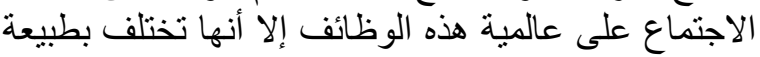

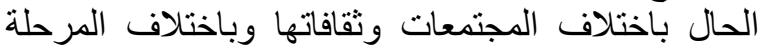
التطورية لكل مجتمع (عمر و الغزوي، واعلة 2006 ).

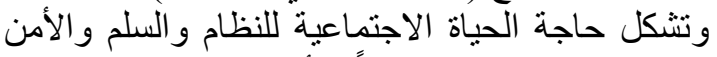
أساسا لظاهرة السلطة نظراً لأهمية توفر الأية الاستقرار الاجتماعي لضمان استمرارية أداء الأنساق الاجنتة الأماعية

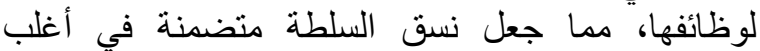

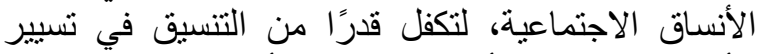

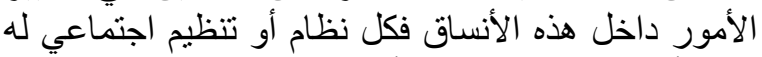

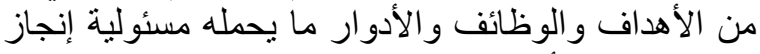

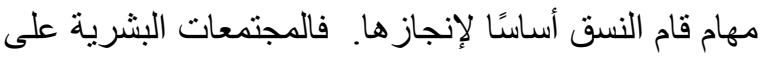


والإستهلاك والعيش المشترك الذي يوطد العلاقات بين

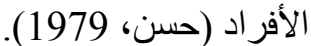
تشير نظرية الإمكانات إلى عاملين إثنين لتوزيع القوة

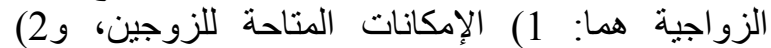

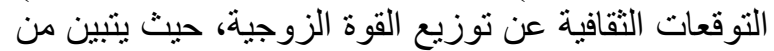

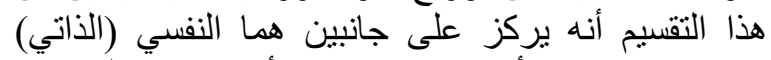

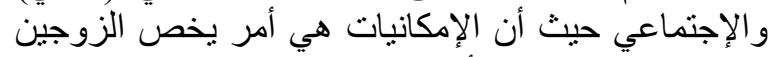

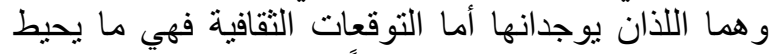

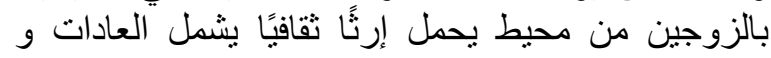
التقاليد وما تحتويه من تصورات حول التئ العلاقة الزوجية،

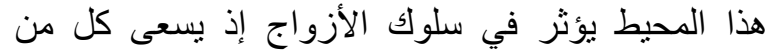

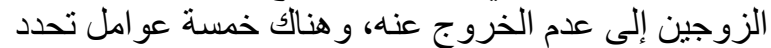
توزيع القوة أو السلطة داخل الأسرة هي (بودون وبوريكو،

1. تتميط الدور : حيث يكون للأزو اج أو الزوجات المقدرة

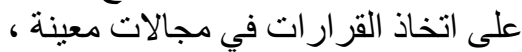

2. الثخصية: حيث تكون سمات الثخصية دافئًا لأمتلاك التك القوة داخل الأسرة.

3. العوامل الثقافية: حيث تدخل في تحدة تلديد المدى الذي الذي يجب أن تكون عليه قوة الزوج أو الزولة الزوجة داخل

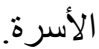

4. السيطرة على الإمكانيات ذات القيمة: فتتوقف القوة على قدر ما يملك الفرد من إمكانيات.

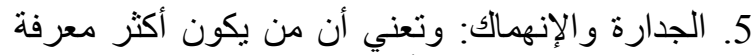

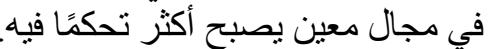
ويمكن القول بأن هناك العديد من العوامل التئ التي تسهر

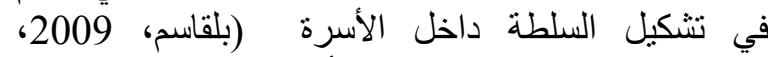
علّيوات، وزيكيلة، 2013 و وأبو حدان، 2011، (Maral \& Kumar, 2017)

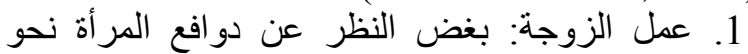

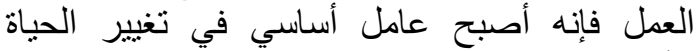

الأسرية إذ يسهم عمل الزوجة في تحقيق استقلالها.

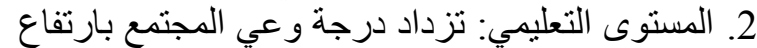

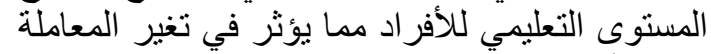

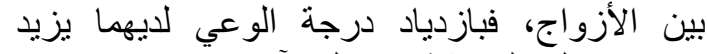
الإعتماد على المناقتشة و تبادل الآراء. الأديا

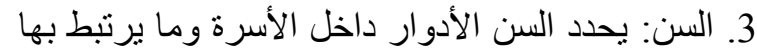
من قوة وسلطة فقدر السلطة التي يمتلكها كبار السن الأن تختلف حتمًا عن الأصغر سنًا.

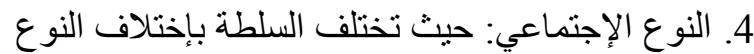
فقوة السيدات تختلف عن قوة الاجتياع الرجال داخل الأسرة

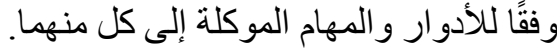
5. تعاليم الدين: حيث يعد الدين مصدراً الدئ أساسيًا لبناء

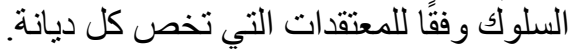

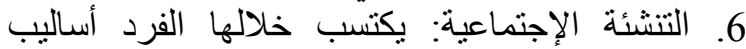

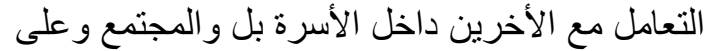
أساسها تتحدد العلاقة بين الذكر و الأنثى.

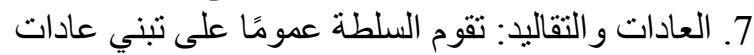
وتقاليد المجتمع لكي تجسد ما يتبناه الأفرادي، فهي
القديمة إلى الحد الذي بعتبر الأب هو زعيم ديني لأعضاء

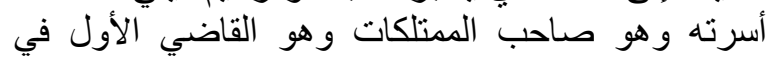

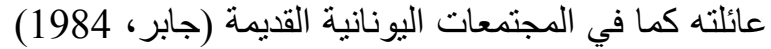
. وتنتقل هذه السلطة إلى الإبن الأكبر بعد وفاة والئن الداه كما

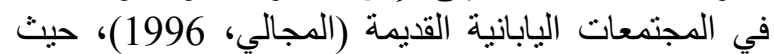

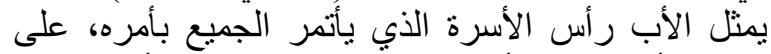

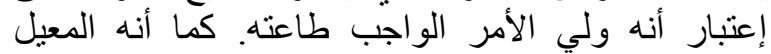
الأساسي ومحور المعلية الإنتاجية مما شكّل سبيًا مبانشرًا لطاعته وذللك في المجتمعات العربية (حطب، الإنت 1976).

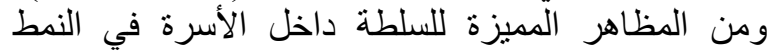
التقليدي، سيادة الذكور، حيث يحتل الذكور، في لالئية الأسرة

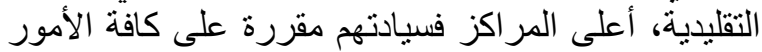
الحياتية نتيجة لإرتباطهم بالأعمال الثاقة وتحملهم الأعباء

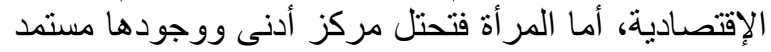

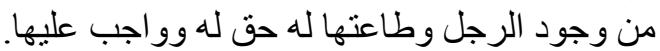

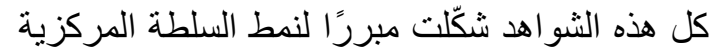

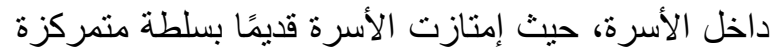

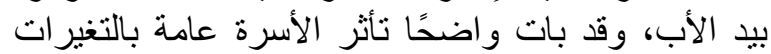

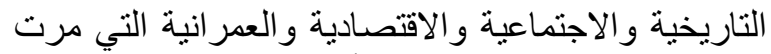

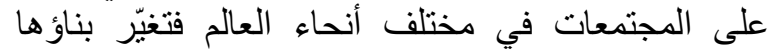
وفقدت كثيرًا من وظتائفها التي كانت في البداية من أسباب

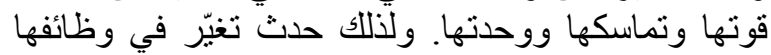

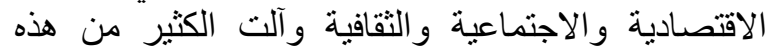
الوظائف كالوظيفة السلطوية إلى مؤسسات أخرى، ولاتية لاسيما

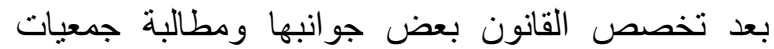

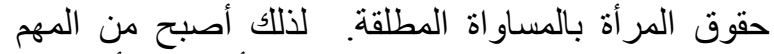

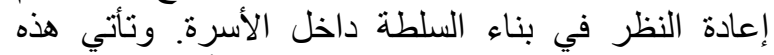

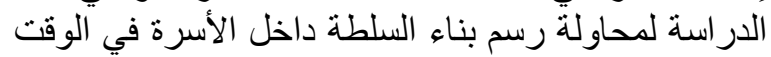

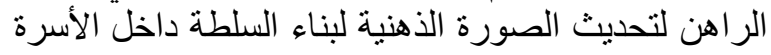

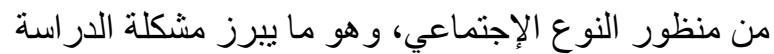
و أهميتها في آن واحد. ومن هذا المنطلق فئن فإنه يمكن بلورة

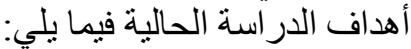
1. التعرف على مدي مشاركة النو ع الإجتماعي في إتخاذ بعض القرارات الأسرية.

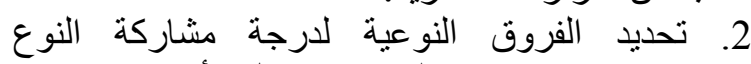
الإجتماعي في إتخاذ القرار الترات داخل الأسرة.

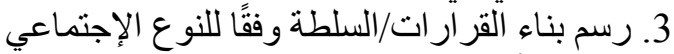

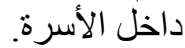

4. التعرف على عو الأل تثنكيل السلطة داخل الأسرة من منظور النوع الاجتماعي.

5. تحديد الفروق النو عبة في عوامل تشكيل السلطة داخل

$$
\text { 2- 2 - 2 الإستعر اض المرجعي }
$$

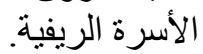

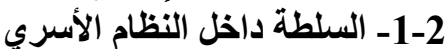

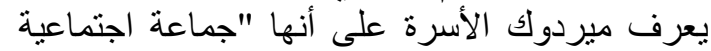

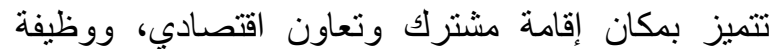
تكاثرية ويوجد بين اثثين من أعضائها على أنى الأقل علاقة

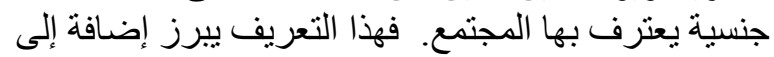
الوظيفة التكاثرية وظيفة التعاون الاقتصادي بالإنتاج 
ويعتبر النوع الإجتماعي مفهومًا ثقافيًا يشمل الأدوار

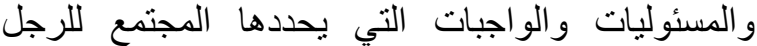

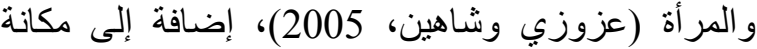

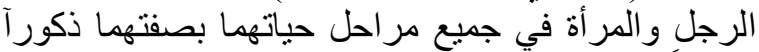

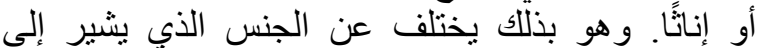

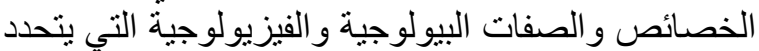
الذكور والإناث على أساسها (حسين، 2016).

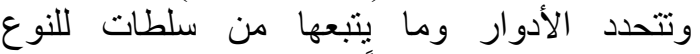

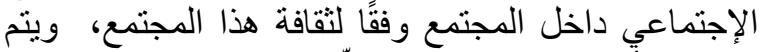

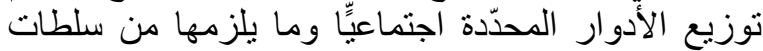

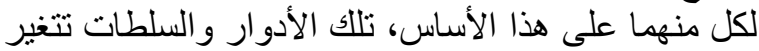

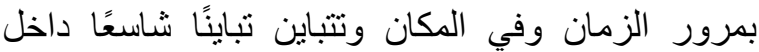

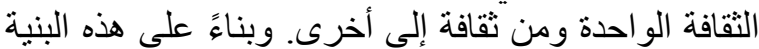

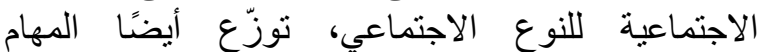

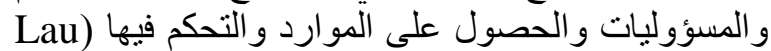

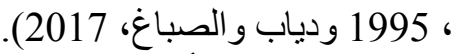
و إذا كانت الأدوار و العلاقات الإجتماعية للرجل فئل

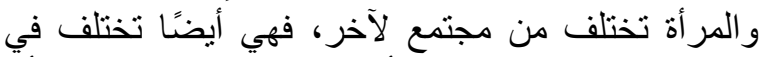

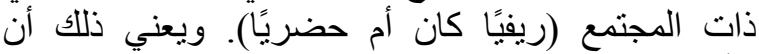

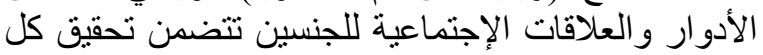

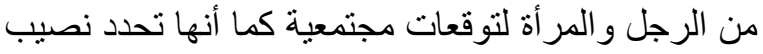

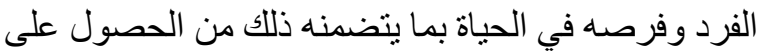

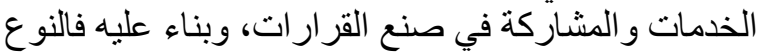

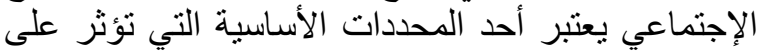

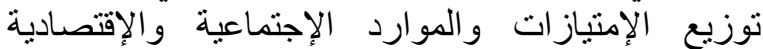
و السلطة وصنع القرارات داخل الأسرة (عزوزي وشاهين،

\section{3ـ - الطريقة البحثية}

1-3 -3 منهجية الدراسة

اعتمدت الدر اسة على عدة مناهج بحثية حيث استخدم

المنهج الوصفي ومنهج المسح الاجتماعي بالعينة، كما لإنة

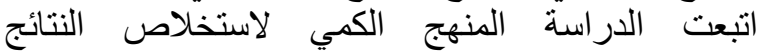

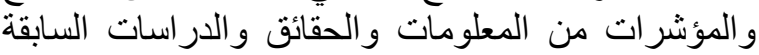

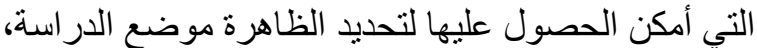

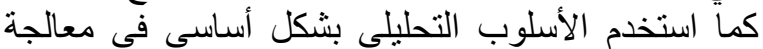

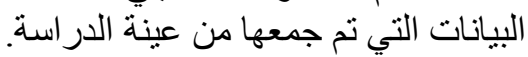
2-3-3 عينة الاراسة الجة

1-2-3-3 المجال الجغرافي لعينة الدراسة: تم اختيار

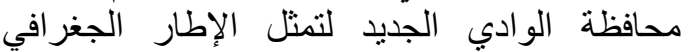

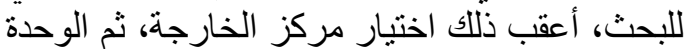

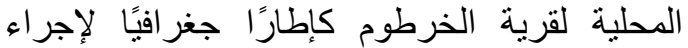
الدر اسة الميدانية. 2-2-3 المجال البشري لعينة الدراسة: بلغ إجمالي عدد الزئة

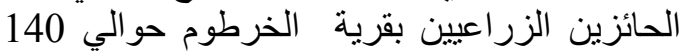

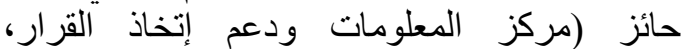
2016)، تبع ذلك سحب عينة عشو الئية قور امها 100 أسرة وفقًا لجدول كريسجي ومورجان لاختيار

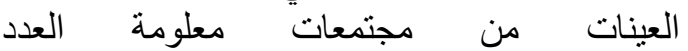
(Krejcie \& Morgan, 1970)
أفضل آلية للسيطرة، إذ يعد الخروج من دائرنها هروجًا عن المجنمع. 8. القانون: يشكل القانون للعديد من الأزواج و الزوجات

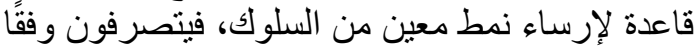
لبنوده المتعلقة بالأحو ال الثخصية لإنية.

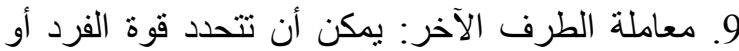

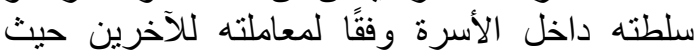
تتطلب السلطة موافقة الأتباع و إنصياعهم لقوة لألرين

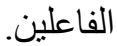

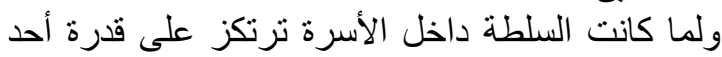

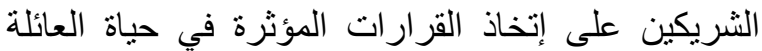

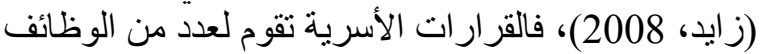

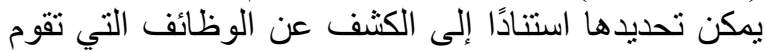
بها الأسرة في المجتمع، على النى النحو التالي (معدري، و الهلي، 2013)

1. وظيفة المحافظة على النمط ومعالجة التوترات:

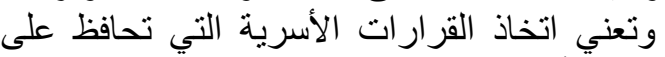
القيم الأسرية،

2. وظيفة التكامل: وتعني اتخاذ القرار ات الأسرية التي

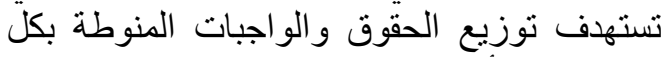

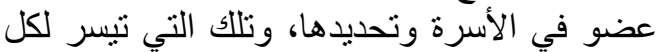

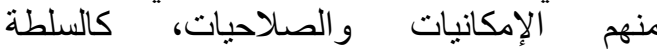

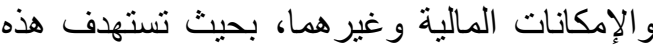
القرارات ضمان التناغم والانسجام بين أعضاء

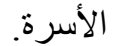

3. وظيفة تحقيق الهدف: الأسرة تحتاج إلى تحديد

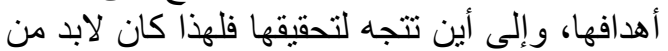

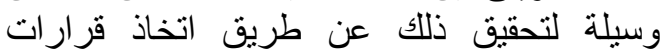
وتتفيذها لتحقيق مصالح الأسرة، كقرارات التهات إدخال

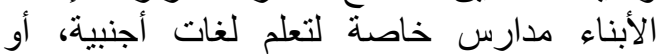
قرارات الإدخار من أجل بناء أو شراء مسكن أجنية جديد. 4. وظيفة التكيف: وتحقق هذه الوظيفة القرارات الأسرية التي تتضمن اكتساب الموارد و الإمكانات التي يمكن أن تستغل في تحقيق اكتيق مطالب الأسرة،

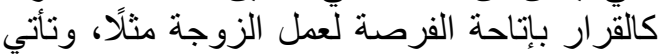
هذه الوظيفة لتحقق التلاؤم للأسرة مع التروة التغيرات

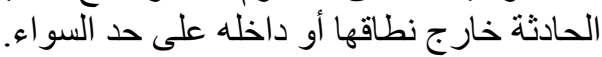

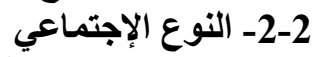

يشير مفهوم النوع الإجنماعنماعي إلى در اسة العلاقة

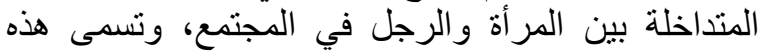

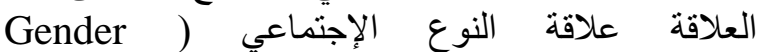

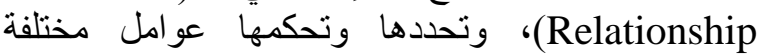

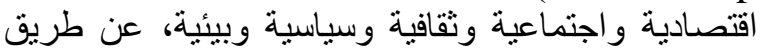
تأثير ها على قيمة العمل في الأدوار الإنجابية والإنتاجية

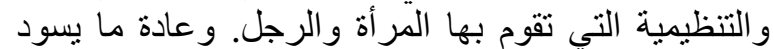

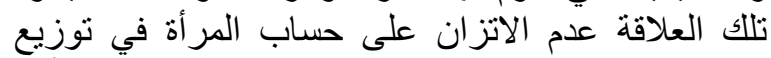

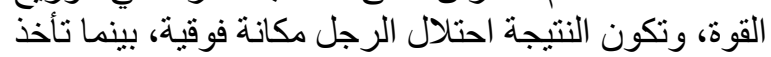

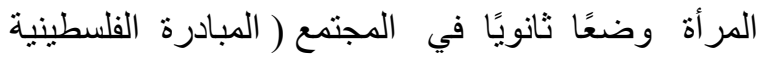
لتعميق الحوار العالمي والديمقا في اطية "مفتاح": 2006). 
3. لا توجد فروق بين المبحوثين من الرجال و النساء فيما

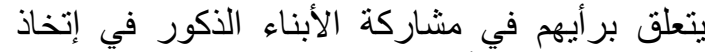
القرارات داخل الأسرة الريفية (الفروض من 21 إلى

4. لا توجد فروق بين المبحوثين من الرجال و النساء فيما

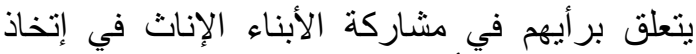
القرارات داخل الأسرة الريفية (الفروض من الأناث في 31 إلى

2-4-3- فروض الهدف الخامس

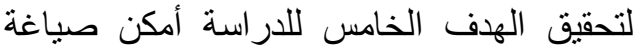

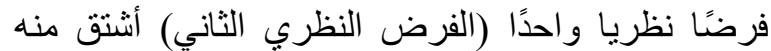

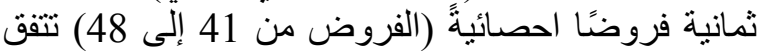

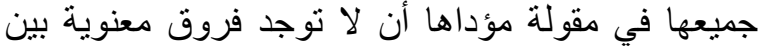

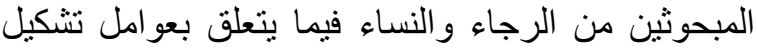

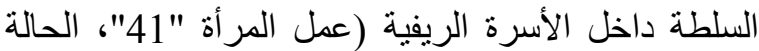

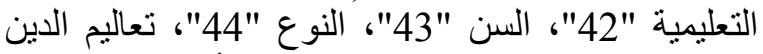

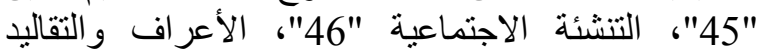

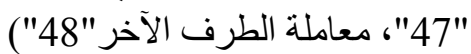
4.3. أدوات التحليل الإحصائي الأي استعانت الدراسة الحالية بمجمو عة من الأساليب

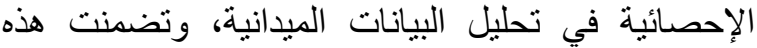

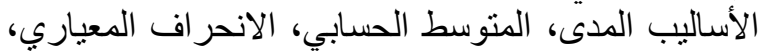
النسب المئوية، وإختبار اختبار (T) للفرق بين منوسطي الإني عينتين مستقلتين.

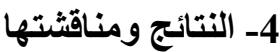

1-4 وصف عينة الدراسة

يوضح الجدول رقم (2) المتغير ات الأسرية في عينة

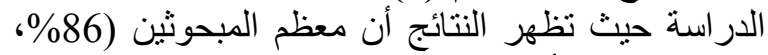

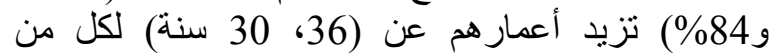

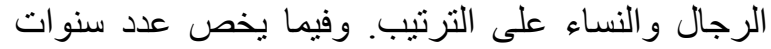

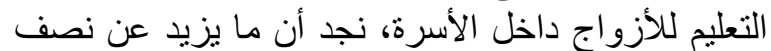

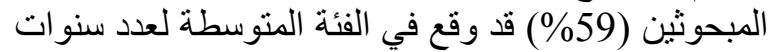

حجم العينة 100 أسرة مزرعية حيث تم سؤال كل من الزوج والزوجة داخل كل أسرة (100 زئة زورجة و100 زوجة الزوج) من الأسر موضع داخع الدر اسة.

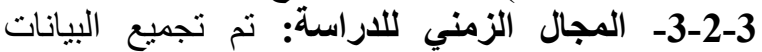

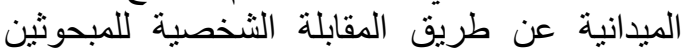
(الأزواج و الزوجات داخل الأسرة) بمنطقة الدراسة الإنة

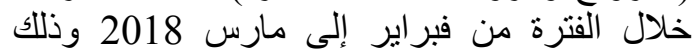

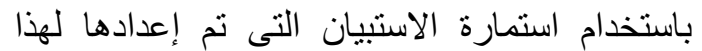

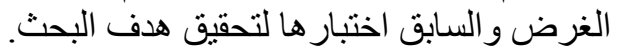

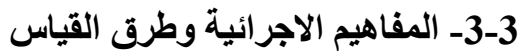
1-3-3-3 بناء السلطة: النمط الذي تتوزي التوع به القوة أو القدرة

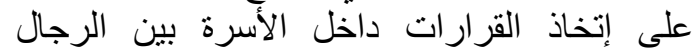

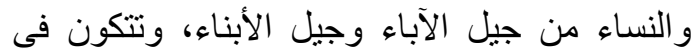
الدر اسة الحالية من ستة أنماط، ثلاثثة للآباء (ذكورية

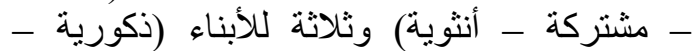
مشتركة - أنثوية) أيضًا.

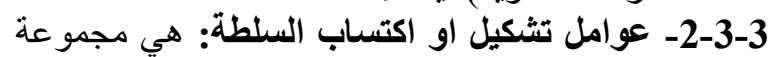

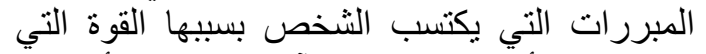
تمكنه من التأثثر على سلوك الآخرين داخل الأسرة. 4-3-3- فروض الاراسنة -1-4-3-3 فروض الهدف الثاني

لتحقيق هدف الدراسة الثئن الثاني تم صياغة فرضًا

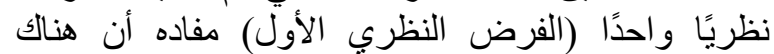

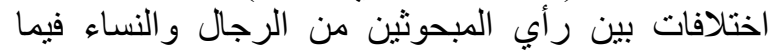

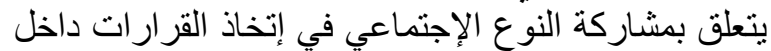

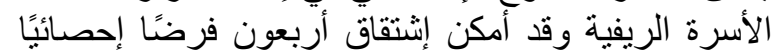

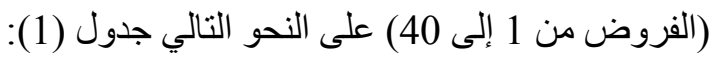

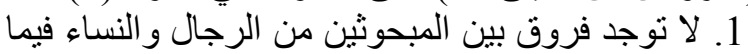

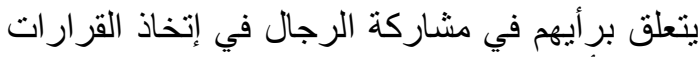

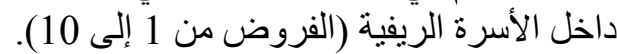

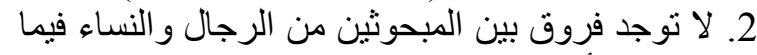

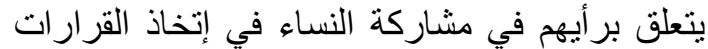
داخل الأسرة الريفية (الفروض من فئر النساء في الذى 20).

جدول (1): مصفوفة الفروض الإحصائية الخاصة بالفروق بين رأي كل من الرجال والنساء في مشاركة النوع الإجتماعي في إتخاذ القرارات داخل الأسرة الريفية (الهذف الثالث للاراسة).

\begin{tabular}{|c|c|c|c|c|c|}
\hline \multicolumn{4}{|c|}{ درجة المشاركة في إتخاذ القرارات بالنسبة لكل من .. } & \multirow{2}{*}{ القرارات ـ رقم الفرض الإحصائي } & \multirow[t]{2}{*}{ م } \\
\hline الأبناء الإناث & الأبناء الذكور & 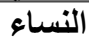 & الرجال & & \\
\hline 31 & 21 & 11 & 1 & قرار شر اء أو بيع أرض زراعية & .1 \\
\hline 32 & 22 & 12 & 2 & قرار شر اء أو بيع معدة أو ماكينة زر اعية & .2 \\
\hline 33 & 23 & 13 & 3 & قرار شر اء أو بيع الحيوانات المزرعية & .3 \\
\hline 34 & 24 & 14 & 4 & قرار شر اء أو بيع الطيور المنزلية & .4 \\
\hline 35 & 25 & 15 & 5 & قر ار شر اء أو بيع مسكن أو شقة & .5 \\
\hline 36 & 26 & 16 & 6 & قر ار شر اء أو بيع المنتجات الزر اعية & .6 \\
\hline 37 & 27 & 17 & 7 & قرار اختيار الددرسة للابناء & .7 \\
\hline 38 & 28 & 18 & 8 & قرار شراء ونوع الملابس لأفراد الأسرة & .8 \\
\hline 39 & 29 & 19 & 9 & قرار نوع الأكل اللازم لأفر اد الأسرة & .9 \\
\hline 40 & 30 & 20 & 10 & إجمالي درجة المشاركة في إتخاذ القرارات & .10 \\
\hline
\end{tabular}


جدول (2): التوزيع العددي والنسبي لعينة الدراسة وفقًا للمتغيرات موضع الدراسة.

\begin{tabular}{|c|c|c|c|c|c|c|c|c|}
\hline الفئة & الفئة & الفئة & الاتحراف & المتوسط & & & 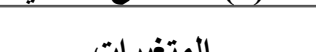 & \\
\hline المرتفعة & المتوسطة & المنخفظة & المعياري & الحسابي & الحـ الأعلى & الحد الأدني & المعيراك & $?$ \\
\hline 42 & 44 & 14 & 8.74 & 45.76 & 62 & 24 & عمر الزوج & .1 \\
\hline 22 & 59 & 19 & 4.87 & 10.60 & 16 & 0 & عدد سنوات تعليم الزورج & .2 \\
\hline 52 & 32 & 16 & 8.64 & 39.88 & 53 & 19 & عمر الزوجة & .3 \\
\hline 4 & 66 & 30 & 5.02 & 8.38 & 16 & 0 & عدد سنو ات تعليم الزوجة & .4 \\
\hline 81 & 15 & 4 & 2.29 & 13.3 & 18 & 8 & طيبعة المسكن & .5 \\
\hline 83 & 11 & 6 & 4.99 & 38.35 & 44 & 20 & مشتملات المسكن & .6 \\
\hline
\end{tabular}

المصدر: الار اسة الميدانية

بنسبة متوسطة. أما فيما يخص رأي أبي الرجال في مشاركة الجيل الثاني

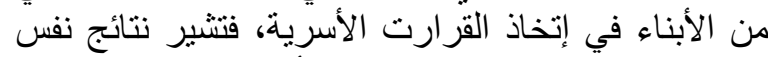
الجدول إلى وقوع 61\% من الأن الأبناء الذكور في فئة

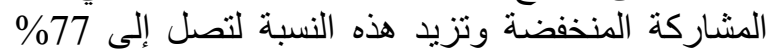

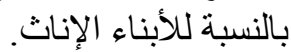

وفيما يتعلق بترتيب الإناث النوع الإجتماعي وفقًا لدرجة

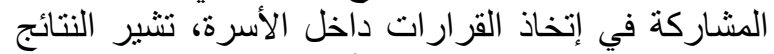

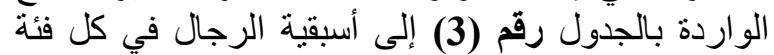
عمرية حيث جاء في المرتبة الأولى الرجال أربأب الربات الأسر

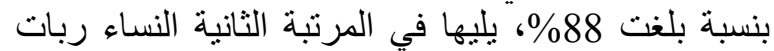

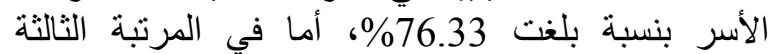
و الرابعة فكان النوع الإجتماعي من جيل الأبناء بنسبة الإبة الإبة

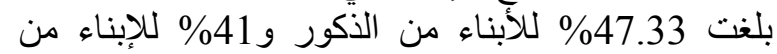

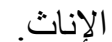

أما فيما يتعلق بتفاصيل ونو عية القرار ات التي يشارك

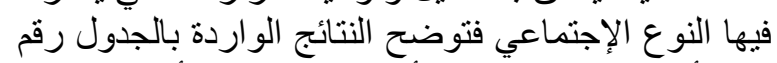

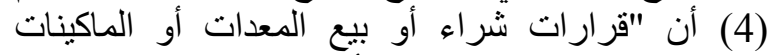

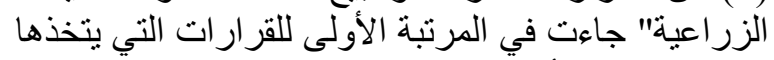

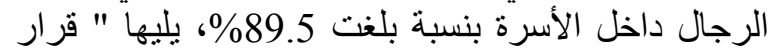

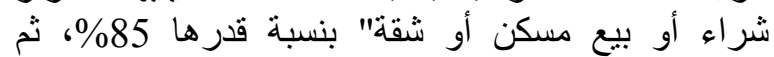

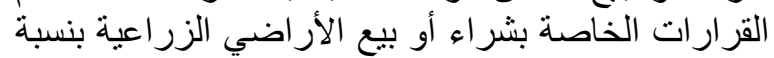

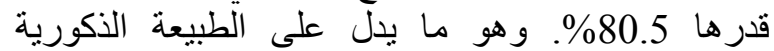
للقرارات الأسرية المتعلقة بالإقتصاد خارج المنزل وإدارة الدكرة

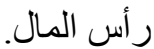

وفيما يتعلق براي الرجال في نوعية القرارات التي

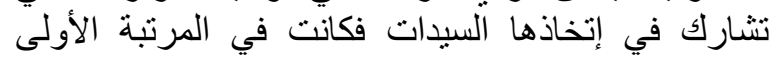

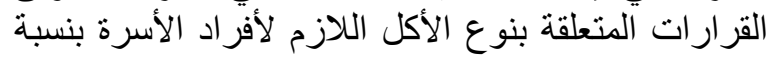

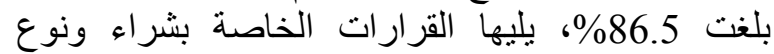

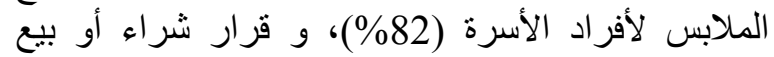

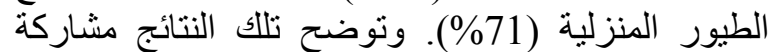
المرأة في إتخاذ القرارات المتعلقة بالإقتصاد المتاد المنزلي. وتثير البيانات الواردة بالجدول رقم (4) أيضًا إلى الإنى

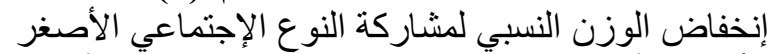

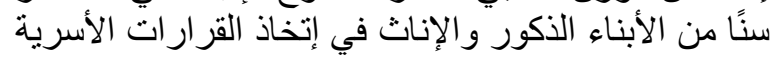

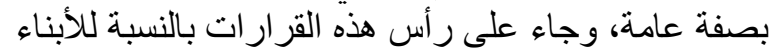

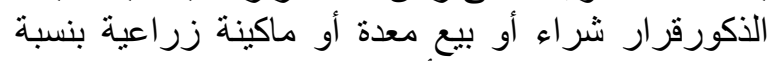

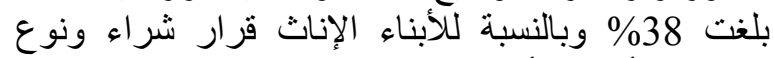
الملابس لأفر اد الأسرة بنسبة بلغت 34\%ة. وجدير بالذكر
التعليم وتزيد هذه النسبة لتصل إلى 66\% في حالة

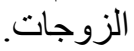

وفيما يخص طبيعة المسكن ومشتملاته، توضح النتائج

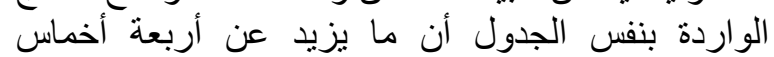
المبحوثين (81\%، و 833\%) قد وقعت مناز لهم ضنمن الفئة المرتفعة لكل من طبيعة المسكن (من حيث موثلث مواد البناء و وغيرها) و ومشتملات المنكن المن (من حيث الأجهزة

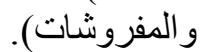

2-4- مشاركة أفراد الأسرة في إتخاذ بعض القرارات الأبرات

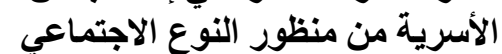

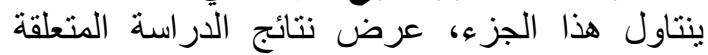

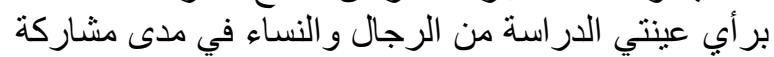

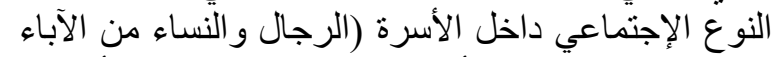

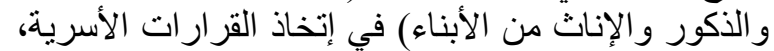

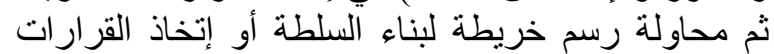

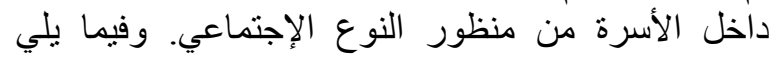

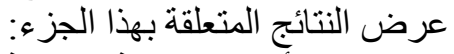

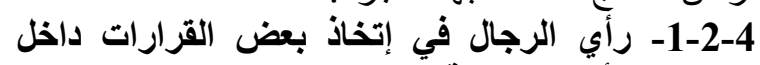

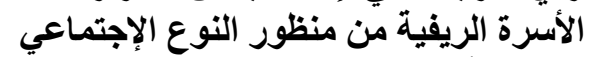

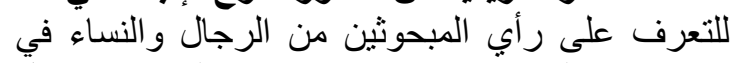

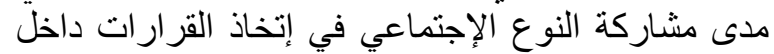

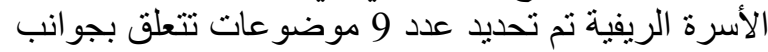

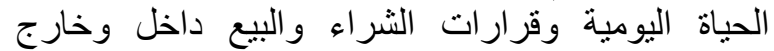

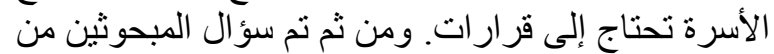

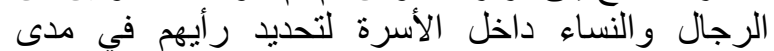

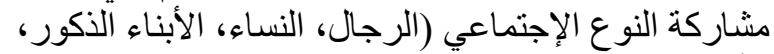

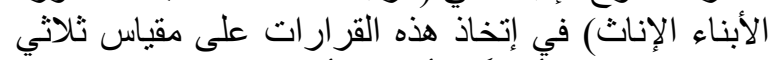

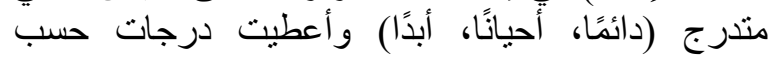

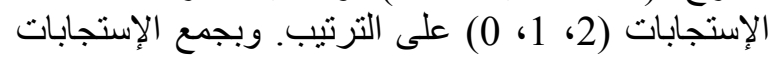

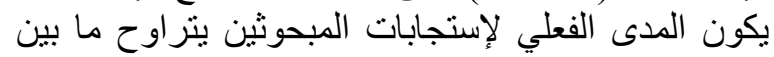

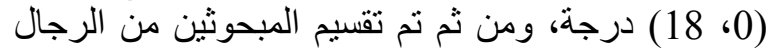

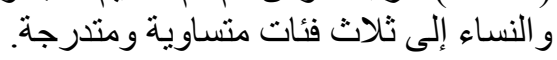
وتثير البيانات الواردة بالجدول رقات رقم (3) إلى إقرار

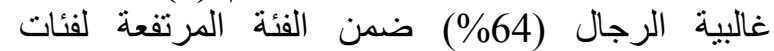
المشاركة في إتخاذ القرارات الأسرية وقد وقال وقع باقي المبحوثين (36\%) في الفئة المنوسطة، في حين خلت الفئة

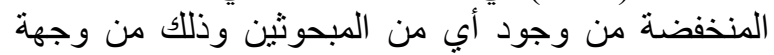

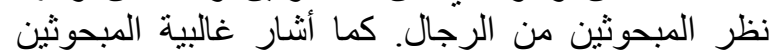

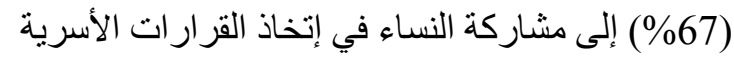


الملابس لأفراد الأسرة (71\%)، و قرار شراء أو بيع الطيور المنزلية (60\%).

وتشير البيانات الواردة بالجدول رقم (6) أيضًا

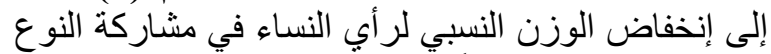

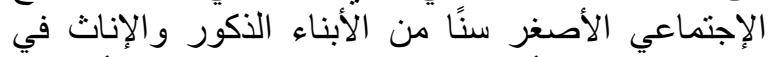

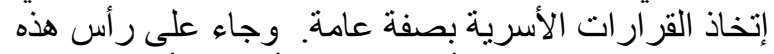

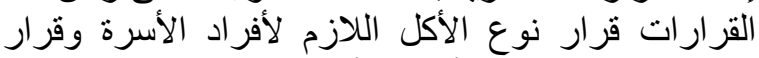

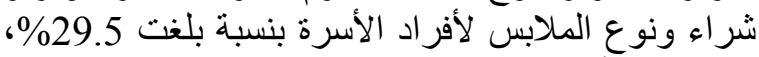

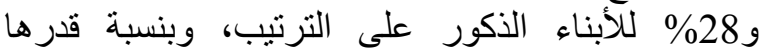

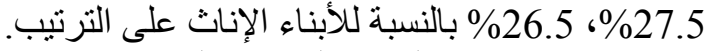
3-4- الفروق النوعية لارجة مشاركة النوع الإجتماعي التاني

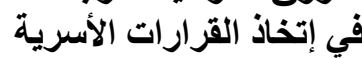

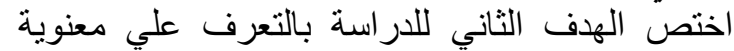
الفروق النوعية لمدى مشاركة النوع الإجتماعي في إنخاذ التاذ

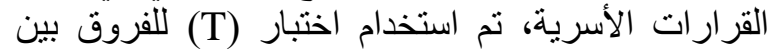

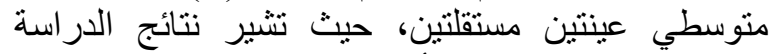

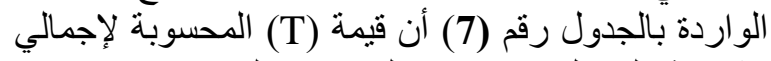

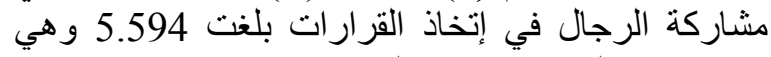
معنوية عند المستوى الاحتمالي 0.01 و هو ما يعني معنوية الرية

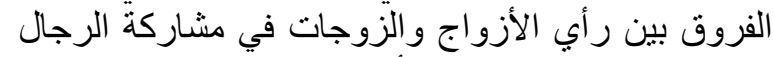
في إتخاذ القرارات داخل الأسرة الريفية. كما تشير نتائج نفس الجدول إلى معنوية الفروق بين رأي التي الأزواج

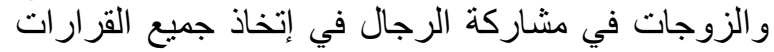

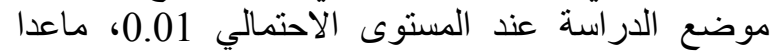
القرار المتعلق بشراء أو بيع الأراضي الزئي الزراعية حيث

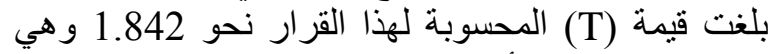
غير معنوية عند أي مستوى إحتمالي. ولذا فلانية فيلا يمكن فئن

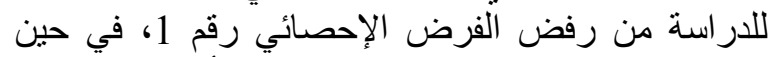
يمكن للار اسة رفض رفض الفروض الإنصائية أرفام من في 2 إلى فين 10 وقبول الفروض للإن البديلة لها. أما فيما يتعلق بمشاركة النساء في القراريلة التهات الأسرية،

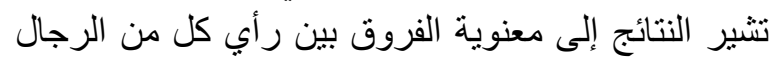

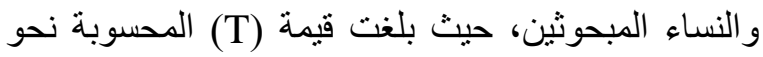
5.713 وهي قيمة معنوية عند المسنوى الإحتمالي 0.01.

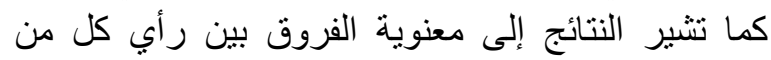

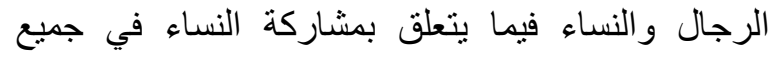

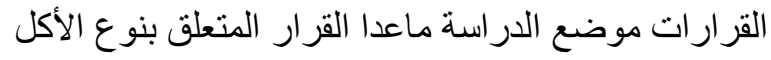
اللازم لأفر اد الأسرة حيث بلغت قيمة (T) المحسوبة لهذا لهات الألئ

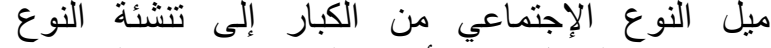

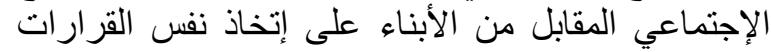
التي يمارسها عنصري النواني من الإناء الإجتماعي من الكبار.

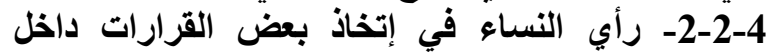
الأسرة الريفية من منظور النوع النوان الإجتماعي الترات

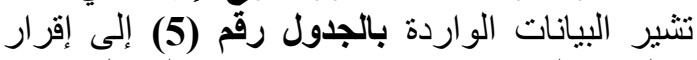

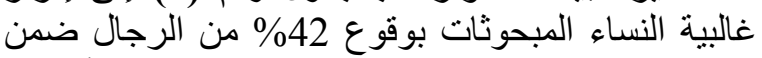

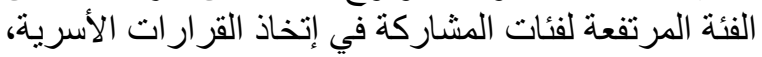

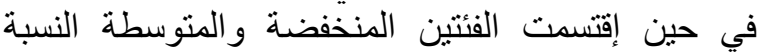

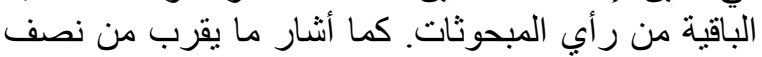

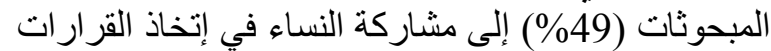

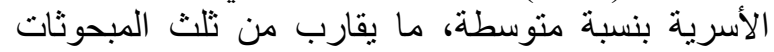
ضمن فئة المشاركة المنخفضة فئة أما فيما يخص رأئارئ النساء في مشاركة الجيل الثناني

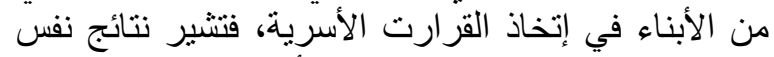
الجدول إلى وقوع 59\% من الأبناء الذكور في فئة الأنة

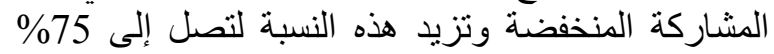
بالنسبة للأبناء الإناث.

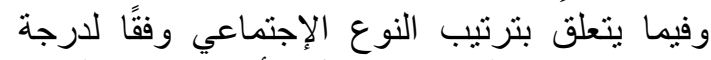

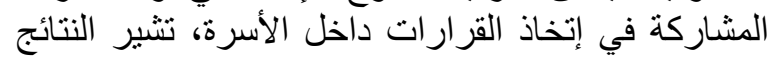

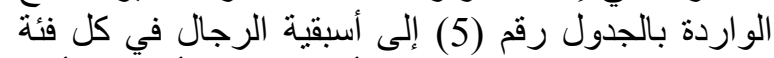

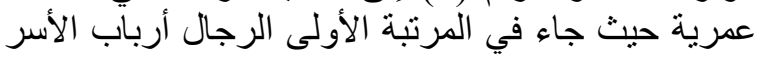

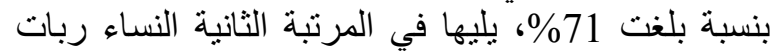
الأسر بنسبة بلغت 62.33\%، أما في المرتبة الثالثة فئة الثات

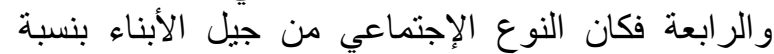
بلغت 48.33\%، 42.33\% ألكل من الأبناء من الأبناء الذكور و الإبناء الإناث على الترتيب.

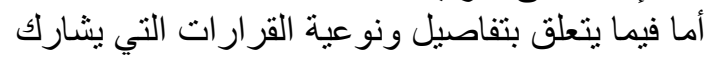

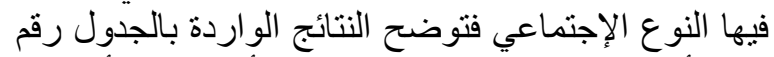

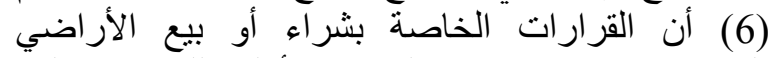
الزراعية قد جاءت في المرتبة الأولى للقرارات التئ التي التي

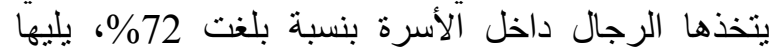

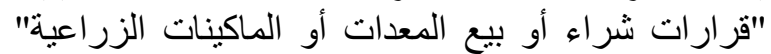

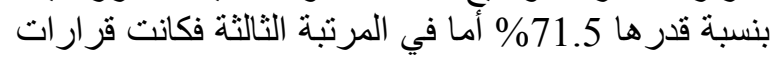

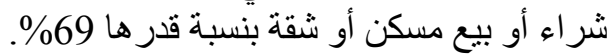

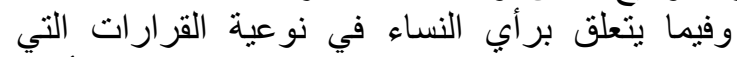

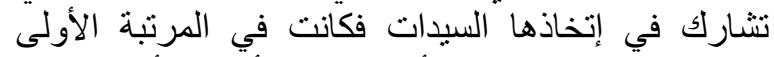

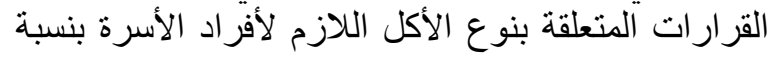

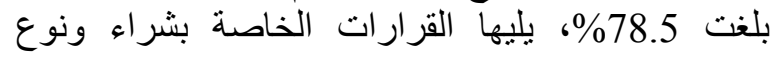

جدول (3) : يبين التوزيع النسبي لرأي الرجال المبحوثين في مدي مثاركة النوع الإجتماعي في اتخاذ القرارات الأسرية.

\begin{tabular}{|c|c|c|c|c|c|c|}
\hline \multirow{2}{*}{ 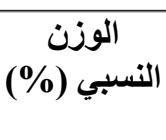 } & \multicolumn{3}{|c|}{ فئات المشاركة في إتخاذ القرارات } & \multirow[b]{2}{*}{ المعياري } & \multirow{2}{*}{ الحستوسطي } & \multirow[t]{2}{*}{ فئات المشاركة } \\
\hline & 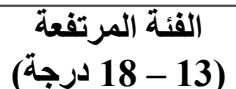 & (7 الفئة المتوسطة 12 درجة) & (الفئة المنخفضة 6 - 6 درجات) & & & \\
\hline 88.00 & 64 & 36 & 0 & 2.72 & 22.29 & الزوج \\
\hline 76.33 & 31 & 67 & 2 & 2.61 & 20.18 & الزوجة \\
\hline 47.33 & 3 & 36 & 61 & 3.89 & 13.96 & الأبناء الذكور \\
\hline 41.00 & 0 & 23 & 77 & 3.44 & 11.99 & الأبناء الإناث \\
\hline
\end{tabular}

المصدر: عينة الاراسة الإنة 
جدول (4): يبين التوزيع النسبي لرأي الرجال المبحوثين في مدي مشاركة النوع الإجتماعي في اتخاذ بعض القرارات الأسرية.

\begin{tabular}{|c|c|c|c|c|c|c|c|c|c|c|c|c|c|c|c|c|c|}
\hline \multicolumn{4}{|c|}{ الأبناء الإناث } & \multicolumn{4}{|c|}{ الأبناء الأكور } & \multicolumn{4}{|c|}{ 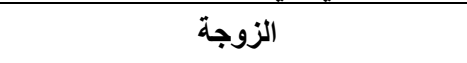 } & \multicolumn{4}{|c|}{ الزوج نفسه } & \multirow{2}{*}{ القرارات } & \multirow[t]{2}{*}{ p } \\
\hline النسبي \% & 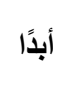 & 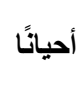 & دائمًا & النسبي \% & أبدًا & 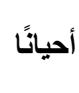 & دائمًا & النسبي \% & أبدًا & أحيانًا & دائمًا & النسبي \% & أبدًا & أحيانًا & دائمًا & & \\
\hline 8.50 & 86 & 11 & 3 & 32.00 & 41 & 54 & 5 & 50.50 & 8 & 83 & 9 & 80.50 & 2 & 35 & 63 & قرار شراء أو بيع أرض زراعية & .1 \\
\hline 8.50 & 88 & 7 & 5 & 38.00 & 39 & 46 & 15 & 42.50 & 20 & 75 & 5 & 89.50 & 2 & 17 & 81 & قرار شراء أو بيع معدة أو ماكينة زراعية & .2 \\
\hline 5.50 & 89 & 11 & 0 & 31.50 & 39 & 59 & 2 & 49.00 & 18 & 66 & 16 & 80.00 & 2 & 36 & 62 & قرار شراء أو بيع الحيوانات المزرعية & .3 \\
\hline 18.50 & 70 & 23 & 7 & 10.00 & 85 & 10 & 5 & 71.00 & 8 & 42 & 50 & 50.00 & 21 & 58 & 21 & قرار شراء أو بيع الطيور المنزلية & .4 \\
\hline 15.00 & 77 & 16 & 7 & 24.00 & 62 & 28 & 10 & 57.00 & 8 & 70 & 22 & 85.00 & 0 & 30 & 70 & قرار شراء أو بيع مسكن أو شقة & .5 \\
\hline 9.50 & 84 & 13 & 3 & 22.00 & 64 & 28 & 8 & 50.50 & 17 & 65 & 18 & 77.00 & 2 & 42 & 56 & قرار شراء أو بيع المنتجات الزراعية & .6 \\
\hline 20.00 & 72 & 16 & 12 & 22.50 & 67 & 21 & 12 & 70.00 & 2 & 56 & 42 & 76.50 & 0 & 47 & 53 & قرار اختيار المدرسة للأبناء & .7 \\
\hline 34.00 & 52 & 28 & 20 & 37.00 & 47 & 32 & 21 & 82.00 & 2 & 32 & 66 & 68.50 & 2 & 59 & 39 & قرار شراء ونوع الملابس لأفراد الأسرة & .8 \\
\hline 30.00 & 54 & 32 & 14 & 31.00 & 51 & 36 & 13 & 86.50 & 0 & 27 & 73 & 57.50 & 11 & 63 & 26 & قرار نوع الأكل اللازم لأفراد الأسرة & .9 \\
\hline
\end{tabular}


جدول (5): يبين التوزيع النسبي لرأي النساء المبحوثات في مدي مشاركة النوع الإجتماعي في اتخاذ القرارات الأسرية.

\begin{tabular}{|c|c|c|c|c|c|c|}
\hline \multirow{2}{*}{ النسبي } & \multicolumn{3}{|c|}{ فئات المشاركة في إتخاذ القرارات } & \multirow[b]{2}{*}{ الالتحراف } & \multirow[b]{2}{*}{ الحستوسطي } & \multirow[t]{2}{*}{ فئات المشاركة } \\
\hline & (الفئة المرتفعة 18 (13 18 & (7 الفئة المتوسطة 12 درجة) & (0 الفئة المنخفضة 6 درجات) & & & \\
\hline 71.00 & 42 & 29 & 29 & 5.47 & 18.87 & 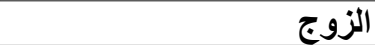 \\
\hline 62.33 & 19 & 49 & 32 & 4.59 & 17.18 & 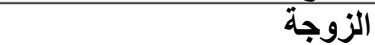 \\
\hline 48.33 & 4 & 37 & 59 & 4.97 & 13.56 & الأبناء الأكور \\
\hline 42.33 & 2 & 23 & 75 & 3.82 & 11.78 & الأبناء الإناث \\
\hline
\end{tabular}

قرار إختبار المدرسة الخاصة بالأبناء كان قرارًا مشتركا بين الرجال والنساء من جيل الآباء. وفيما يتعلق بالسلطة أو القرارات الأباء التي يتخذها الأبناء

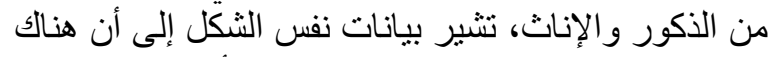

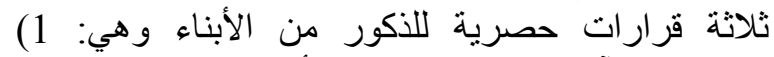

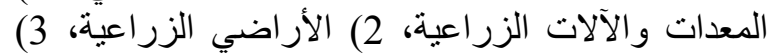

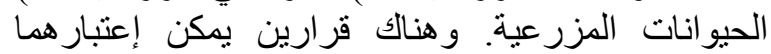

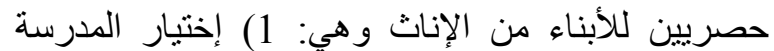

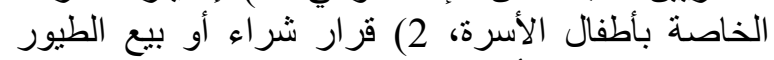

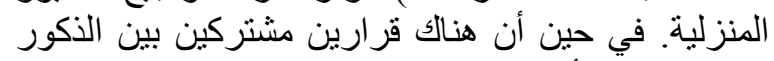

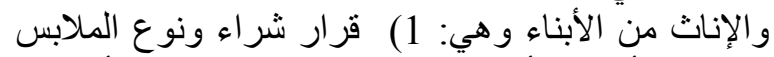

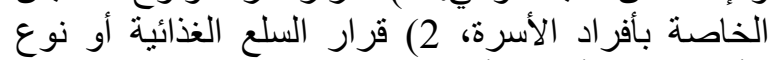
الأكل اللازم لأفر اد الأسرة.

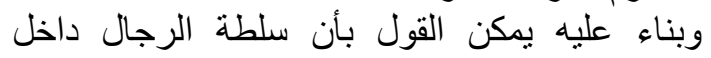

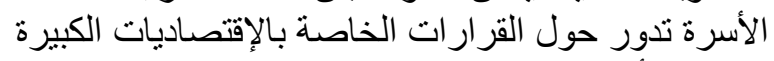

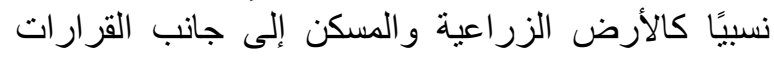

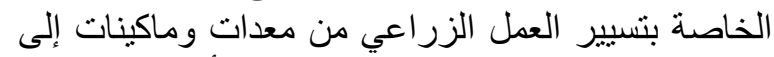
جانب تسويق المنتجات الزر اعية. في حين أن سلطة النئ النساء

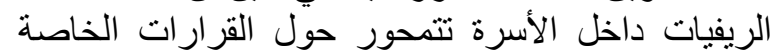

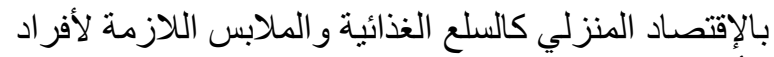

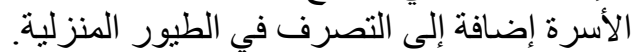

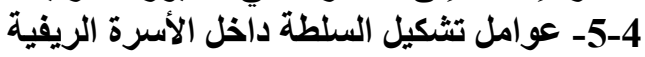

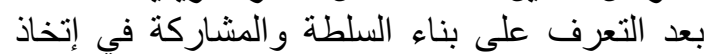

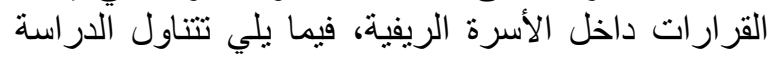

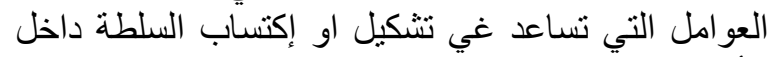

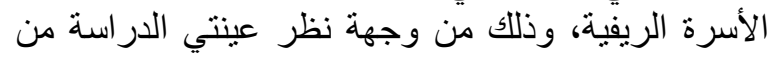

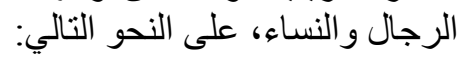
1-5-4- رأي الرجال في عوامل تثنكيل السلطة داخل الأسرة

للتعرف على رأي المبحوثين من الرجال في عوامل

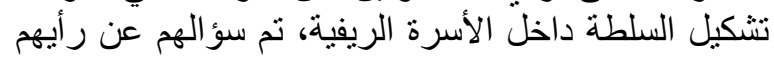

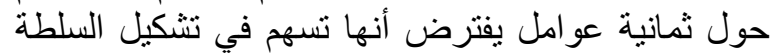

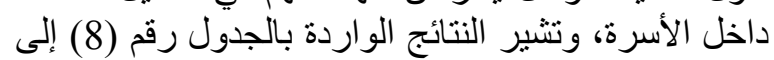

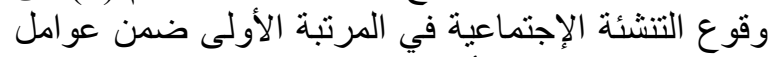

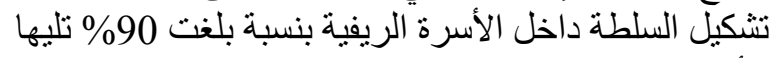

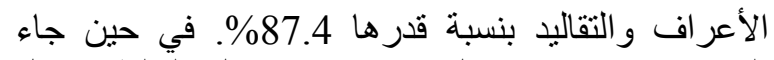

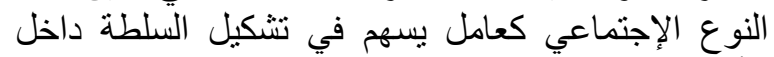

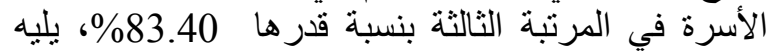
الحالة التعليمية في المرتبة الر ابعة بنسبة قدر ها 82.6\%ة \% \%
القرار نحو 1.832 وهي غير معنوية عند أي مستوى

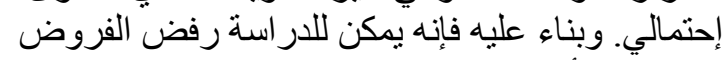

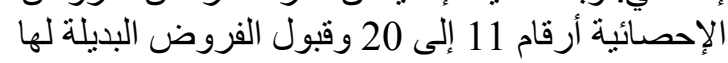
ماعدا الفرض رقم الأنم 19.

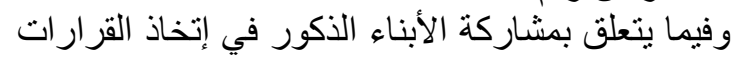

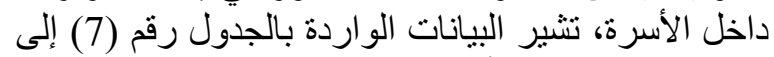

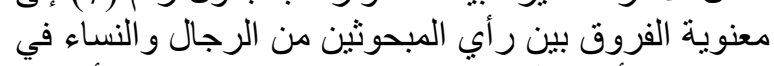

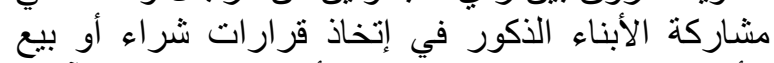

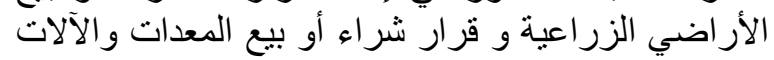

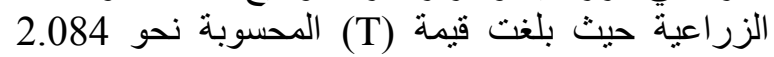

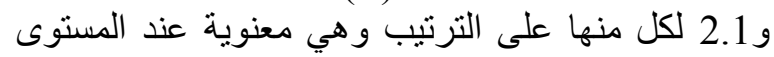

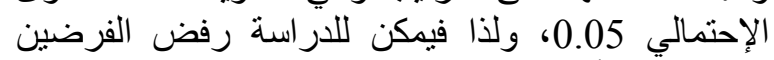

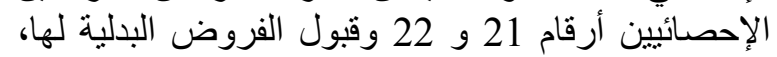

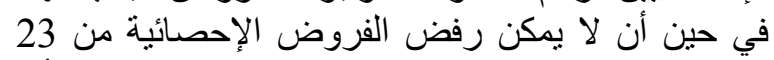

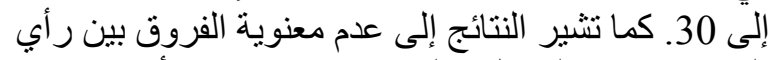

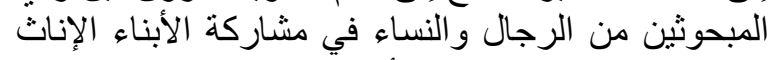

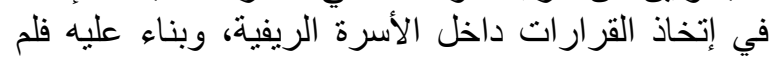
تتمكن الدراسة من رفض أي من الفروض الأرة أرقام 31 إلى

4-4-4 بناء القرارات/السلطة وفقًا للنوع الإجتماعي داخل الأسرة

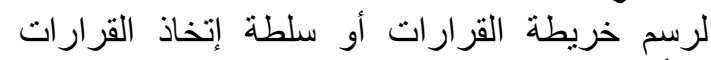

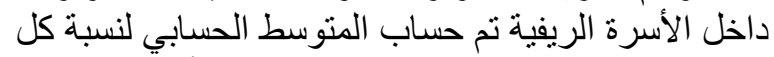

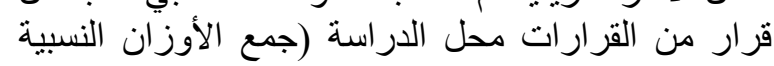

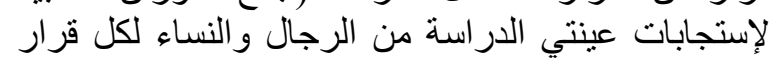

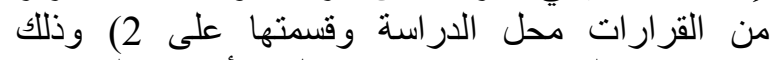

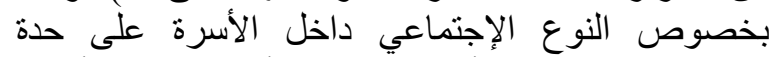

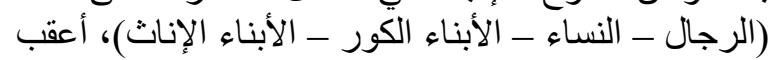

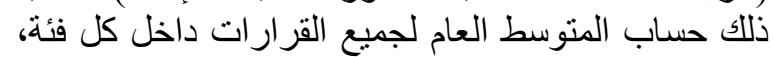
ثم تم إعتبار القرارات التي تزيد عن التمات المتوسط الحسابي

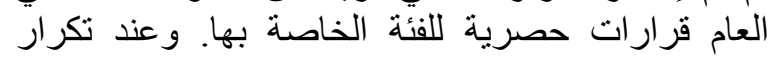
القرار كقرار حصري في فئتي النوع يتم إعتباره قرارًا

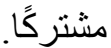
وتثشير بيانات الشكل رقم (1) أن هنالك خمسة قرار ات

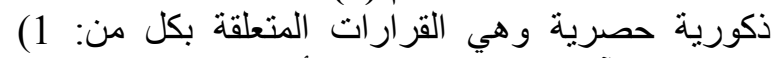

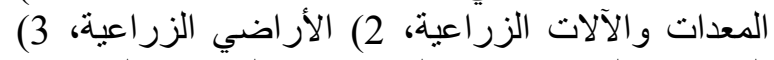

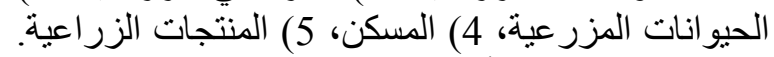

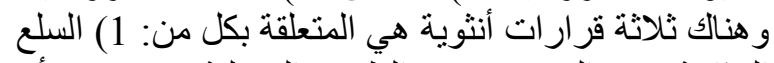
الغذائية، 2) الملابس، 3) الطُّيور المنزلية، في حين أن الن 
جدول (6): يبين التوزيع النسبي لرأي النساء المبحوثات في مدى مشاركة أفراد الأسرة في اتخاذ بعض القرارات الأسرية.

\begin{tabular}{|c|c|c|c|c|c|c|c|c|c|c|c|c|c|c|c|c|c|}
\hline \multicolumn{4}{|c|}{ الأبناء الإناث } & \multicolumn{4}{|c|}{ الأبناء الذكور } & \multicolumn{4}{|c|}{ الزوجة نفسها } & \multicolumn{4}{|c|}{ 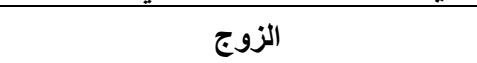 } & \multirow{2}{*}{ القرارات } & \multirow[t]{2}{*}{ م } \\
\hline النسبي الوزن & أبدًا & أحيانًا & دائمًا & النسبي \% الوزن & 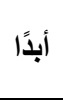 & 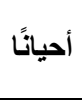 & دائمًا & النسبي \% الوزن & 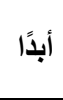 & أحيانًا & دائمًا & النسبي أوزن & أبدًا & أحيانًا & دائمًا & & \\
\hline 7.50 & 85 & 15 & 0 & 23.00 & 62 & 30 & 8 & 23.00 & 58 & 38 & 4 & 72.00 & 16 & 24 & 60 & قرار شراء أو بيع أرض زر اعية & .1 \\
\hline 11.50 & 82 & 13 & 5 & 27.50 & 58 & 29 & 13 & 20.50 & 65 & 29 & 6 & 71.50 & 20 & 17 & 63 & زراعية شراء أو بيع معدة أو ماكينة & .2 \\
\hline 8.50 & 85 & 13 & 2 & 22.00 & 62 & 32 & 6 & 26.00 & 63 & 22 & 15 & 66.50 & 29 & 9 & 62 & 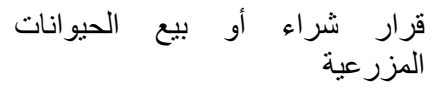 & .3 \\
\hline 15.00 & 74 & 22 & 4 & 9.00 & 84 & 14 & 2 & 60.00 & 30 & 20 & 50 & 22.50 & 67 & 21 & 12 & قرار شراء أو بيع الطيور المنزلية & .4 \\
\hline 16.00 & 79 & 10 & 11 & 27.00 & 63 & 20 & 17 & 41.50 & 43 & 31 & 26 & 69.00 & 20 & 22 & 58 & قرار شر اء أو بيع مسكن أو شقة & .5 \\
\hline 6.50 & 89 & 9 & 2 & 26.00 & 65 & 18 & 17 & 30.00 & 59 & 22 & 19 & 57.00 & 37 & 12 & 51 & قرار شر اء أو بيع المنتجات الزر اعية & .6 \\
\hline 20.00 & 72 & 16 & 12 & 26.00 & 62 & 24 & 14 & 58.50 & 23 & 37 & 40 & 55.50 & 33 & 23 & 44 & قرار اختيار المدرسة للأبناء & .7 \\
\hline 26.50 & 63 & 21 & 16 & 28.00 & 60 & 24 & 16 & 71.00 & 19 & 20 & 61 & 42.50 & 45 & 25 & 30 & قرار شراء ونوع الملابس لأفراد & .8 \\
\hline 27.50 & 60 & 25 & 15 & 29.50 & 56 & 29 & 15 & 78.50 & 16 & 11 & 73 & 37.00 & 50 & 26 & 24 & قرار نوع الأكل اللازم لأفر اد الأسرة & .9 \\
\hline
\end{tabular}


جدول (7): نتائج اختبار "T" للفرق بين متوسطي درجة مشاركة أفراد الأسرة في إتخاذ القرارات الأسرية لعينتي الدراسة من منظور النوع

\begin{tabular}{|c|c|c|c|c|c|}
\hline الإناث في القرارة الأبناء & مشاركة الأبناء الذكور & في القرارات الزوجة & في القراراتة الزوج & القرارات & م \\
\hline 0.347 & 2.084 & ${ }^{* *} 7.752$ & 1.842 & قرار شر اء أو بيع أرض زر اعية & .1 \\
\hline 0.829 & 2.100 & 5.702 & 3.883 & قرار شر اء أو بيع معدة أو ماكينة زر اعية & .2 \\
\hline 1.130 & 0.064 & *4.854 & 2.584 & قرار شر اء أو بيع الحيو انات المزر عبة & .3 \\
\hline 0.855 & 0.297 & 2.029 & 5.745 & قرار شر اء أو بيع الطيور المنزلية & .4 \\
\hline 0.224 & 0.586 & *3.179 & 3.462 & قرار شر اء أو بيع مسكن أو شقة & .5 \\
\hline 0.985 & 0.798 & *4.142 & 3.713 & قرار شراء أو بيع المنتجات الزر اعية & .6 \\
\hline 1.000 & 0.691 & *2.438 & 4.164 & قر ار اختبار المدرسة للأبناء & .7 \\
\hline 1.370 & 1.650 & 3.315 & 5.172 & قر ار شر اءونوع الملابس لأفراد الأسرة & .8 \\
\hline 0.482 & 0.293 & 1.823 & 4.039 & قرار نوع الأكل اللازم لأفر اد الأسرة & .9 \\
\hline 0.408 & 0.633 & 5.713 & *5.594 & الإجمالي & \\
\hline
\end{tabular}

المصدر: عينة الاراسة

شكل (1): بناء السلطة/القرارات داخل الأسرة الريفية.

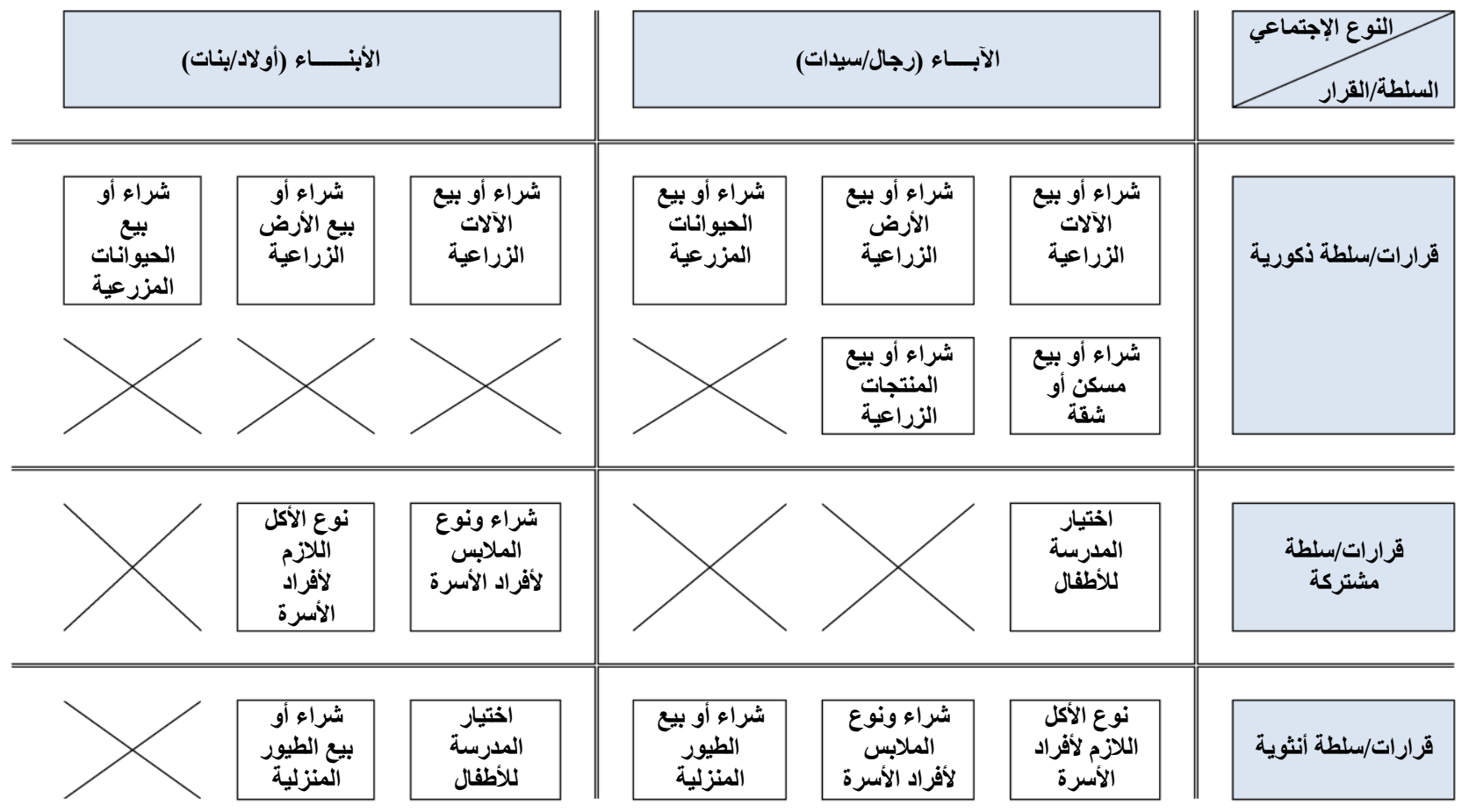

المصدر: حسبت من بيانات الجدولين أرقام (4) و (6).

جدول (8): يبين التوزيع النسبي لرأي الرجال المبحوثين في عوامل تثكيل السلطة داخل الأسرة.

\begin{tabular}{|c|c|c|c|c|c|c|c|c|}
\hline الترتيب & 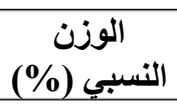 & غير موافق & غير موافق & محايد & موافق & موافق جدًا & عوامل تثكيل السلطة & م \\
\hline 7 & 75.20 & 4 & 14 & 10 & 41 & 30 & عمل المر أة & .1 \\
\hline 4 & 82.60 & 0 & 16 & 12 & 15 & 57 & الحالة التعليمية & .2 \\
\hline 6 & 77.40 & 4 & 9 & 21 & 28 & 38 & السن & .3 \\
\hline 3 & 83.40 & 3 & 5 & 10 & 36 & 46 & النوع & .4 \\
\hline 5 & 77.60 & 0 & 17 & 18 & 25 & 40 & تعاليم الدين & .5 \\
\hline 1 & 90.00 & 0 & 2 & 12 & 20 & 66 & التنشئة الاجتماعية & .6 \\
\hline 2 & 87.40 & 0 & 0 & 13 & 37 & 50 & الأعر اف و التقاليد & .7 \\
\hline 8 & 53.40 & 19 & 21 & 43 & 8 & 9 & معاملة الطرف الآخر & .8 \\
\hline
\end{tabular}


جدول (10)): نتائج اختبار "T" للفرق بين متوسطى درجة عوامل

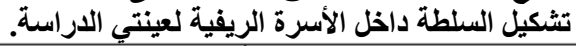

\begin{tabular}{|c|c|c|}
\hline قيمة "T" & عوامل تشكيل السلطة & \\
\hline 0.330 & عمل المر أة & .1 \\
\hline 0.874 & الحالة التعليمية & .2 \\
\hline 0.895 & السن السن & .3 \\
\hline 0.414 & النوع الإجتماعي & .4 \\
\hline 0.121 & تعاليم الدين & .5 \\
\hline 1.808 & التنشئة الاجنماعية & .6 \\
\hline 0.154 & الأعر اف و التقاليد & .7 \\
\hline 0.083 & معاملة الطرف الآخر & .8 \\
\hline
\end{tabular}

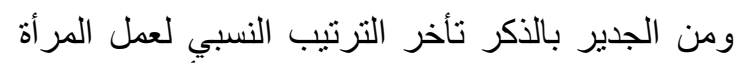
كعامل من عو امل نشكيل السلطة داخل الأسرة الريفية،

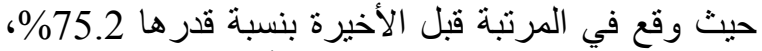

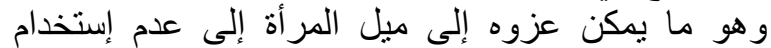
قدر اتها المالية في فرض عز سلطاتها داخل المل الأسرة.

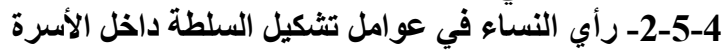

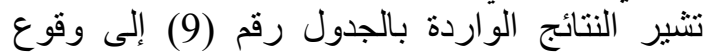

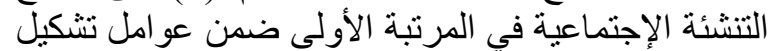

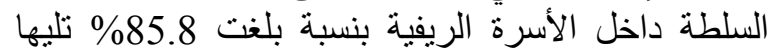

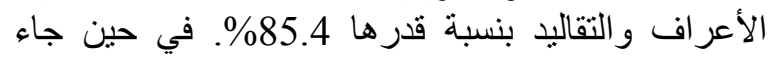

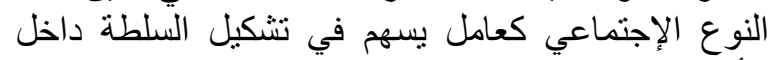

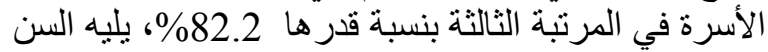
كأحد عوامل تشكيل السلطة في المرتبة الرابعة بنسة

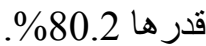

جدول (9) : يبين التوزيع النسبي لرأي النساء المبحوثات في عو امل تثكيل السلطة داخل الأسرة.

\begin{tabular}{|c|c|c|c|c|c|c|c|c|}
\hline الترتيب & $\begin{array}{c}\text { الوزن (النسبي } \\
\text { (\%) }\end{array}$ & غير موافقً & غير موافق & محايد & موافق & موافق جدًا & عوامل تثكيل السلطة & م \\
\hline 7 & 75.00 & 9 & 16 & 13 & 15 & 47 & عمل المر أة & .1 \\
\hline 5 & 79.80 & 0 & 19 & 5 & 34 & 42 & الحالة التعليمية & .2 \\
\hline 4 & 80.20 & 0 & 11 & 23 & 20 & 46 & السن السن & .3 \\
\hline 3 & 82.20 & 0 & 9 & 22 & 18 & 51 & النوع & .4 \\
\hline 6 & 77.20 & 4 & 13 & 18 & 23 & 42 & تعاليم الدين & .5 \\
\hline 1 & 85.80 & 0 & 1 & 23 & 22 & 54 & التنشئة الاجتماعية & .6 \\
\hline 2 & 85.40 & 0 & 1 & 19 & 32 & 48 & الأعر اف و التقاليد & .7 \\
\hline 8 & 57.00 & 19 & 23 & 29 & 12 & 17 & معاملة الطرف الآخر & .8 \\
\hline
\end{tabular}

الخلاصة و التوصيات

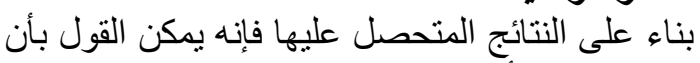

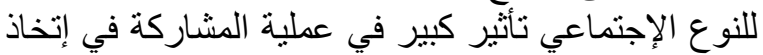

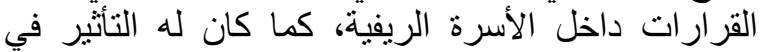

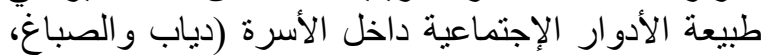

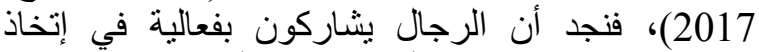

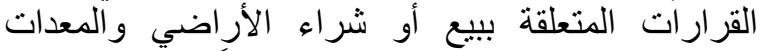

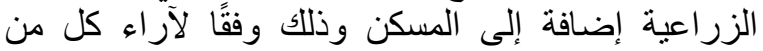

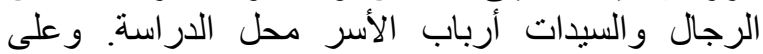

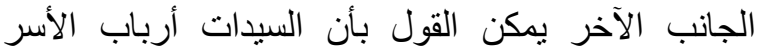

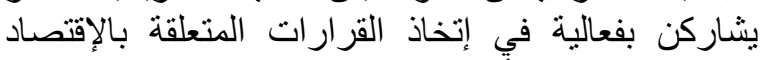

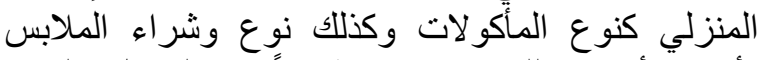

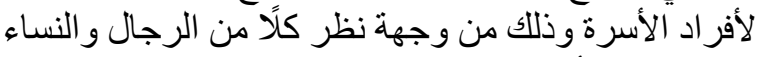

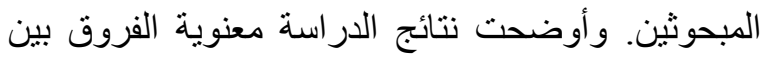

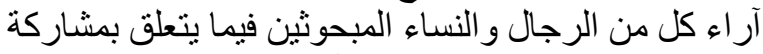
النوع الإجتماعي من جيل الآباء في إنخاذ القرارات النيات

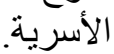

أما فيما يتعلق بمشاركة النوع الإجتماعي لجيل

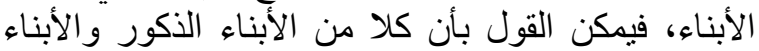

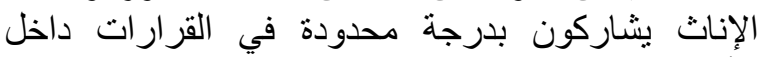
الأسرة وتنحصر مشاركتهم في إختيار وشئر وشراء الملابس دأخل
ومن الجدير بالذكر تأخر الترتيب النسبي لعمل المرأة

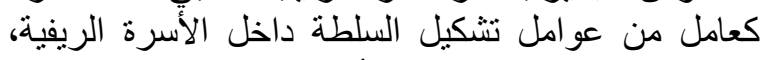

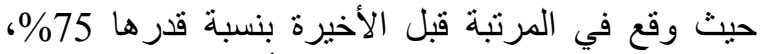
وهو ما يمكن عزوه إلى ميل المرأة إلى إلى عدم إستخدام

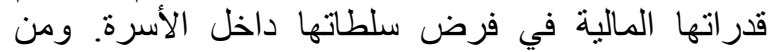

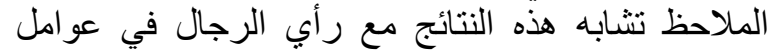

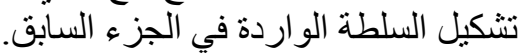
6-4- الفروق النوعية لعوامل تثثكيل السلطة داخل الأسرة الريفية

اختص الهية الخامس للار اسة بالتعرف علي معنوية

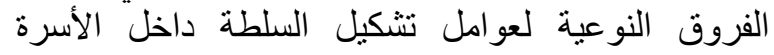
الريفية، ولتحقيق هذا الهدف نم استخدام اختبار (T) للفرق الأني بين متوسطي عينتين مستقلتين، حيث تشئن التبر نتائج الدراسة

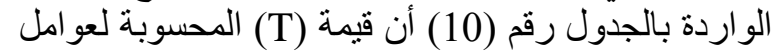

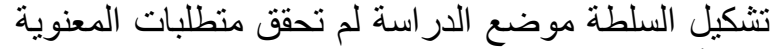

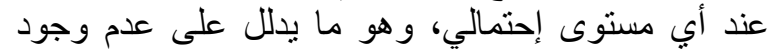

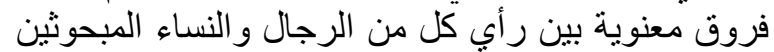
فيما يتعلق بعوامل تشكيل السلطة داخل الألئ السرة الرئل الريفية. و هو ما يشير إلى عدم إمكانية رفض الفيل الفروض الإلىل الإحصائية أرقام من ما ندير اللى 41 إلى 48. 
حسين، حسناء (2016). النوع الاجتماعي: المفهوم و الخصائص، مدونات هافينغتون بوست، مناح الاحئ

http://www.huffpostarabi.com/hasnahussein/-13 b 8109350.html حطب، زهير (1976). تطور بنى الأسرة العربية. الطبعة

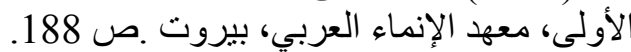
دياب، هند مختار ومحمد صابر الصباغ (لإعياء (2017). التحليل النوعي للاور الإجتماعي في الأسرة الريفية الجية الجية بمحافظة الوادي الجديد. مجلة إتحاد الجامعات الإنيات

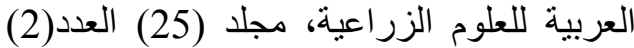

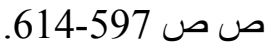

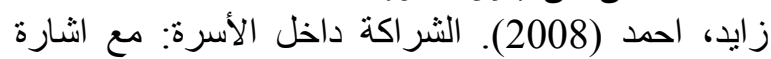
خاصة إلى الأسرة العربية. المجلة العربية الإنة لعلم العارة

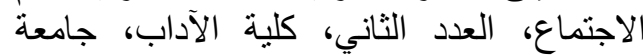

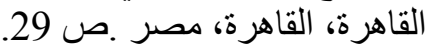

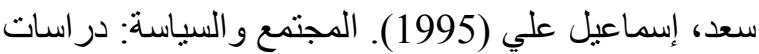

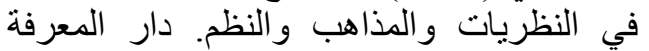
الجامعية، الإسكندرية. ص ول 148. عزوزي، سهير وزينب شاهين (2005). دليل تدريب الايب

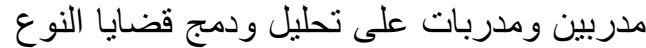
الإجتماعي في التربية. مكتب اليونسكو الإقليمي

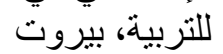

عليو ات، سميحة و بن حسان زينة (2013). عو امل تشكيل

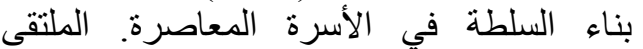

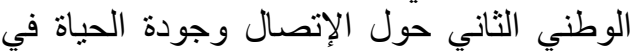
الأسرة، قسم العلوم الإجتماعية، كلية العالية العلوم الإنسانية والاجتماعية، دامعة قاصنية الإعدي مرباح ورقلة، الجز ائر ص الاجنماعة 2-8.

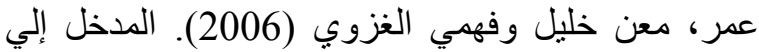

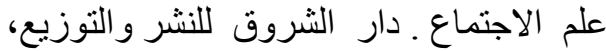

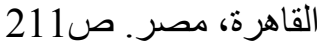
عودة، محمد (1977). أسس علم الاجتماع ـ دار النهضة

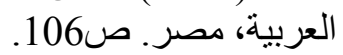

الخولي، سناء (1984). الأسرة والحياة العائلية. دار

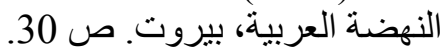

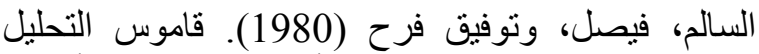

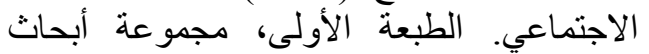

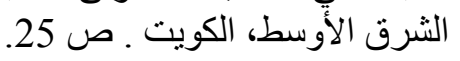

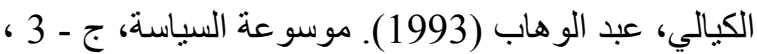

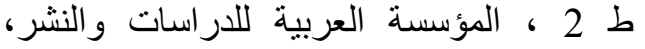

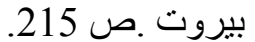
المبادرة الفلسطينية لتعميق الحوار العالمي والديمقراطية

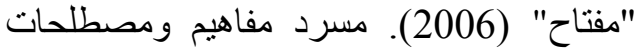

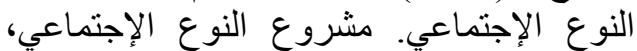

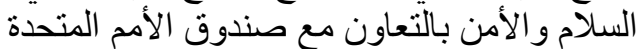

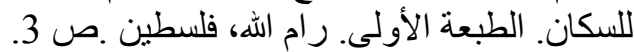

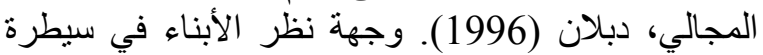

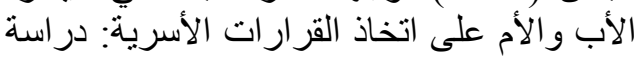

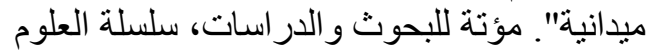

ونوعية المأكو لات اللازمة لأفر اد الأسرة، علاوة على عدم الرمج

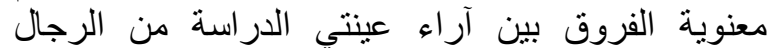
والنساء فيما يتعلق بمشاركة الأبناء في إتخاذ القرار الترات

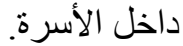
أما بخصوص عوامل تشكيل السلطة داخل الأسرة

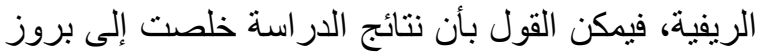

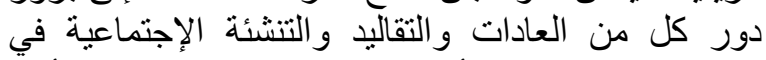

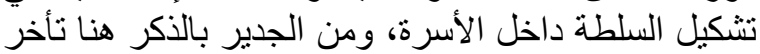

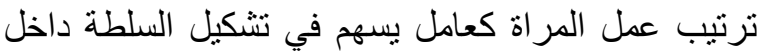
الأسرة على عكس المنوقع، حيث كان من المن التوقع أن يسهر

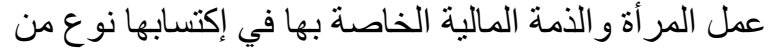

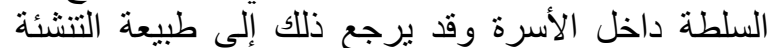

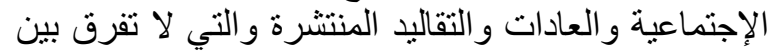

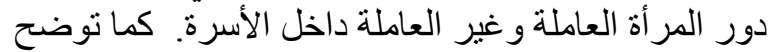

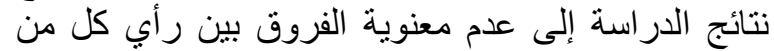
الرجال والنساء المبحوثين فيما يتعلق بعوامل تلثن تشكيل السلطة داخل الأسرة الريفية. وبناء على النتائج المتحصل إلئهة الئها يمكن التوصية بما يلي: 1. ضرورة التوسع في الدراسات التي التئنت التناول عناصر

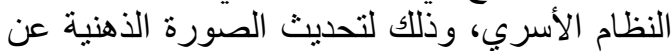
الأسرة الريفية في ظل المتغير ات المعات المعاصرة. 2. الإهتمام بتوثيق الثقافة الموروثة والثئة والعادات و التقاليد

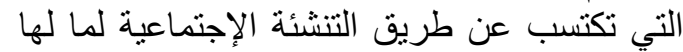
من أهمية في رسم هيكل السلطة داخل النظام الأسري، و النظم الإجتماعية بصفة عامة.

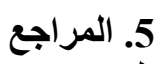

أبو حدان، ماجد ملحم (2011). طرائق التنشئة الاجتماعية الأسرية وعلاقتتها بمدى مشاركة

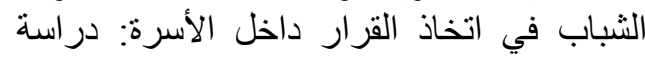

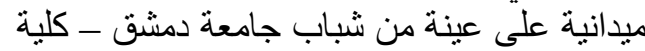

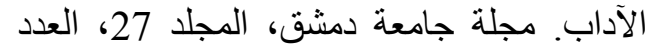

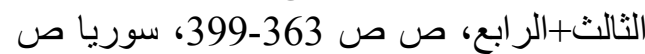
.375-374

بلقاسم، الحاج (2009-374). المرأة و مظاهر تغيّر النظام الأبوي في الأسرة الجزائرية: دراسة ميدانية النية النية

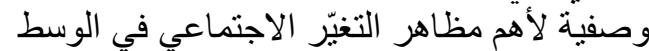

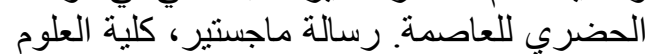

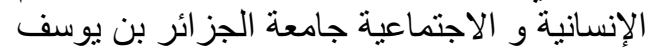

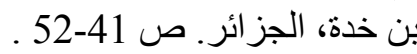
بودون، ر. و ف. بوريكو (1986). الدعجم النقدي لعلم

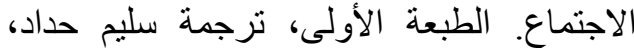

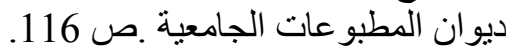

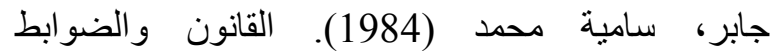

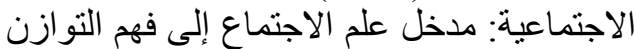

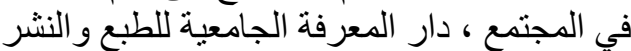
و التوزيع، الإسكندرية.

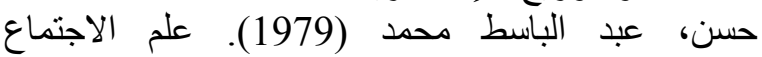
الصناعي. الطبعة الثانية، مكتبة غريب، القاهرة.

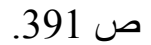


Krejcie R, Morgan D. (1970). Determining sample size for research activities, Educational and Psychological Measurement. 30:607-610

Lau A. (1995). Gender; power and relationships, Ethno-cultural and religious issues. In: C. Burk \& Speed B. (Red.), Gender, power and relationships. London: Routledge, pp. 110-117.

Maral P. and Kumar V. (2017). Family structure and decision-making power among working and non-working women. IAHRW Int'1 J. Soc. Sci., 5(4): 574-580.
الإنسانية والاجتماعية، جامعة مؤتة، مؤتة.

الأردن، المجلد الحادي عشر، العدد الثالثة صؤنة صؤنة

40

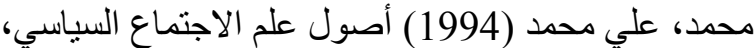

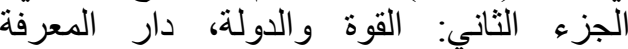

الجامعية، الإسكندرية.

معري، حمزة ومصباح الهلي (2013). قرار الإلة الثراء

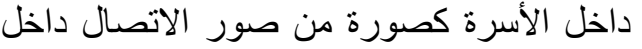

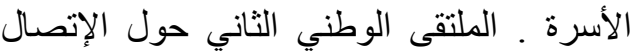

وجودة الحياة في الأسرة. قسم العلوم الإجتماعية، الإنة الإنة

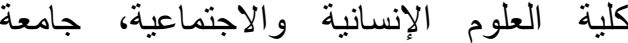

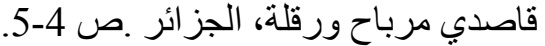

